\title{
Brook Trout (Salvelinus fontinalis) preference of aquatic versus terrestrial prey in Appalachian Headwater Streams
}

\author{
Erin E. Thayer
}

Follow this and additional works at: https://researchrepository.wvu.edu/etd

\section{Recommended Citation}

Thayer, Erin E., "Brook Trout (Salvelinus fontinalis) preference of aquatic versus terrestrial prey in Appalachian Headwater Streams" (2016). Graduate Theses, Dissertations, and Problem Reports. 6790. https://researchrepository.wvu.edu/etd/6790

This Thesis is protected by copyright and/or related rights. It has been brought to you by the The Research Repository @ WVU with permission from the rights-holder(s). You are free to use this Thesis in any way that is permitted by the copyright and related rights legislation that applies to your use. For other uses you must obtain permission from the rights-holder(s) directly, unless additional rights are indicated by a Creative Commons license in the record and/ or on the work itself. This Thesis has been accepted for inclusion in WVU Graduate Theses, Dissertations, and Problem Reports collection by an authorized administrator of The Research Repository @ WVU. For more information, please contact researchrepository@mail.wvu.edu. 
Brook Trout (Salvelinus fontinalis) preference of aquatic versus terrestrial prey in Appalachian Headwater Streams

\author{
Erin E. Thayer
}

\begin{abstract}
Thesis submitted to
the Davis College of Agriculture, Natural Resources, and Design

at West Virginia University
\end{abstract}

in partial fulfillment of the requirements for the degree of

Master of Science in

Wildlife and Fisheries Resources

Kyle J. Hartman, Ph.D., Chair

Stuart A. Welsh, Ph.D.

Yong-Lak Park, Ph.D.

School of Natural Resources

Morgantown, WV

2016

Keywords: Brook Trout (Salvelinus fontinalis), Appalachian Headwater Streams, Riparian Subsidies, Terrestrial Invertebrate Prey, Aquatic Macroinvertebrates 


\title{
ABSTRACT \\ Brook Trout (Salvelinus fontinalis) preference of aquatic versus terrestrial prey in Appalachian Head-water Streams
}

\begin{abstract}
Erin E. Thayer
This thesis aims to investigate the foraging behavior of Brook Trout (Salvelinus fontinalis), specially focusing on prey preference. Brook Trout are mainly restricted to headwater streams in Appalachia, which is a portion of their native range. These environments generally have low autochthonous materials. Therefore, resident aquatic organisms rely heavily on terrestrial inputs, i.e. leaf litter and terrestrial invertebrates ( $\mathrm{Tl}$ 's), to subsidize individual energy requirements at critical times of the year. There is mixed evidence demonstrating stream dwelling trout show either a feeding preference towards aquatic invertebrates (Al's) or towards TI's. Chapter one is an in depth literature review of headwater stream systems, and the external and internal factors contributing to prey selection by riverine trout species. Chapter two encompasses our observational field study of four select streams contained in the Monongahela National Forest, West Virginia. Since these streams are contained in the national forest, they are relatively unimpaired and allowed for adequate numbers of Brook Trout to be collected. These samples were compared to kicknet samples representing Al's available in the environment. Results show a clear trend, in that, Brook Trout forage on Al's overall, in relatively equal proportions to prey availability in spring and summer. Individual taxa preferences did change as well as size selection across seasons, potentially indicating in the springtime they are foraging more on the benthos and from the drift as well as being more size selective.

Furthermore, individual variability exists in which preferences and specialization was shown for either Al's or Tl's in each season. These results suggest Brook Trout are operating under the Optimal Foraging Theory. Brook Trout have the propensity to change their foraging behavior in a short amount of time which will allow them to combat future anthropogenic changes if management efforts are focused on both the surrounding terrestrial landscape (i.e. riparian corridor) as well as the in stream habitat restoration.
\end{abstract}




\section{Acknowledgments}

I would like to thank my committee members:

Dr. Kyle J. Hartman-Thank you for allowing me to explore a project of my own interest from the ground up and guiding me through the scientific method process. Also, thank you for always keeping things interesting with good humor.

Dr. Yong-Lak Park-Thank you for your encouragement throughout this process and exposing me to the world of insects.

Dr. Stuart A. Welsh- Thank you for your help in the statistics involved in my thesis, always being available for questions, and introducing me to the diversity of freshwater fishes.

To the Hartman Lab:

Daniel Hanks, PhD. Candidate- Thank you for your continuous encouragement and good talks while traveling to field sites.

Ross Andrew, PhD. Candidate- Thank you for demonstrating what it is to be a leader, friend and above all, how to pronounce 'Appalachia'.

-Good Luck to you both

To the Undergraduate Volunteers and Interns:

Charlee Cramer

Wendall Hofer

Garrett Richardson

Tyler Plum

Jimmy "Two-Pinch" Hartley

Ben Walton

-I could not have done this study without you

Thank you to those involved in technical assistance for my thesis:

Vicki Kondo-Terrestrial Insect Identification

Donna Hartman-Aquatic Insect Identification

Dr. Chris Rota-Statistics

Dr. Donald Brown-Statistics

Dr. Ida-Statistics

Thank you to funding sources:

West Virginia Department of Natural Resources

USDA Forest Service 
Table of Contents

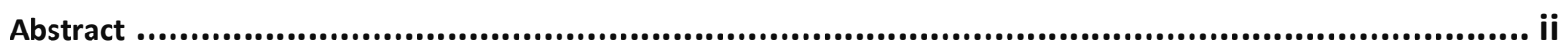

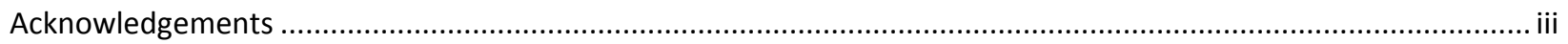

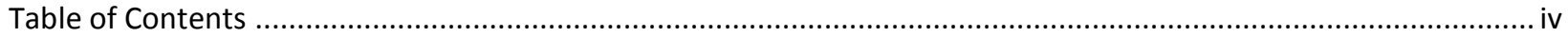

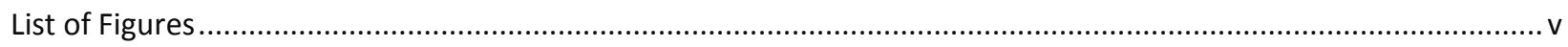

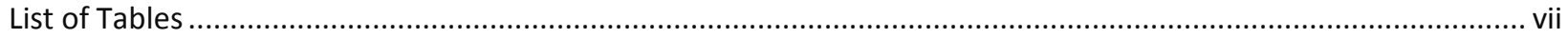

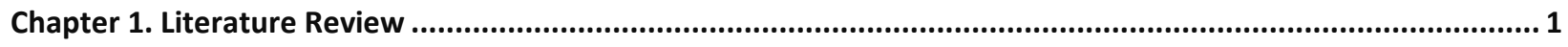

Terrestrial and Aquatic Linkages via Headwater Streams .............................................................

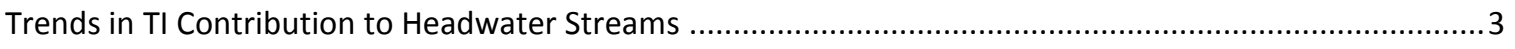

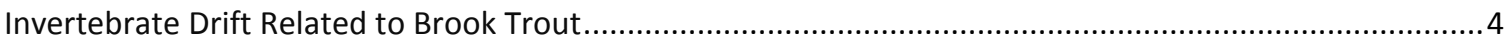

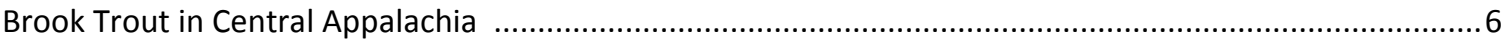

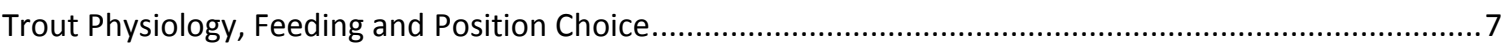

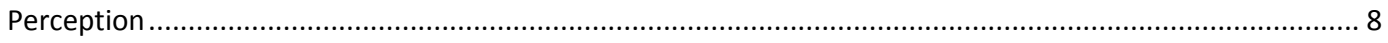

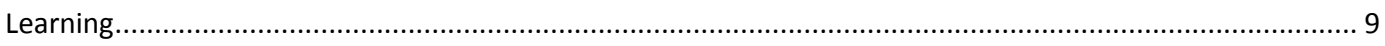

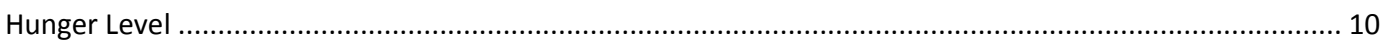

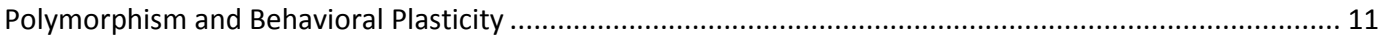

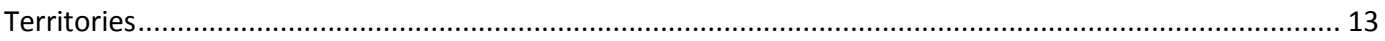

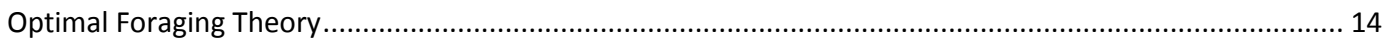

Research on Brook and Other Trout Diets and Prey Preference .........................................................17

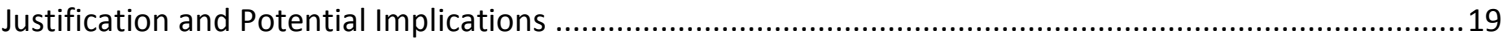

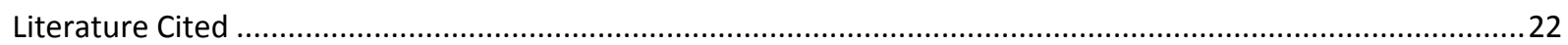

Chapter 2: Terrestrial versus Aquatic Prey Preference by Trout in Appalachian Headwater Streams: Do Brook

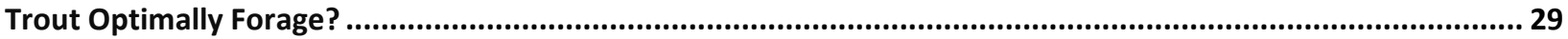

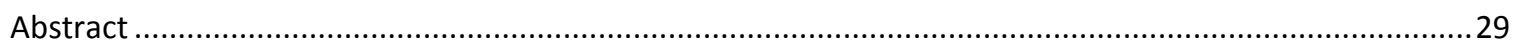

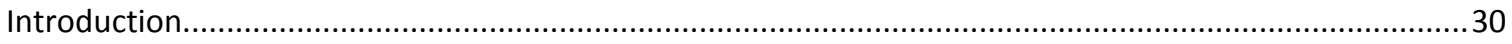

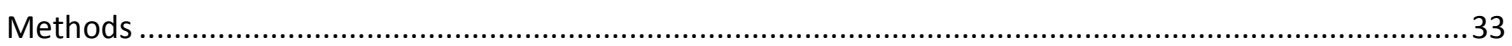

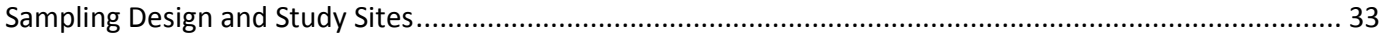

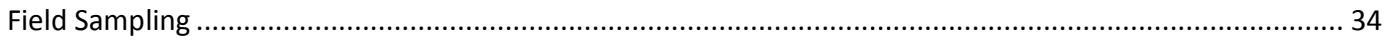

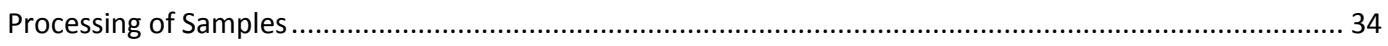

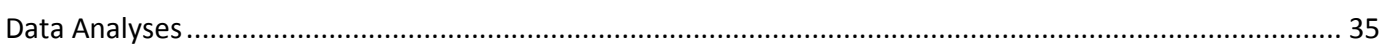

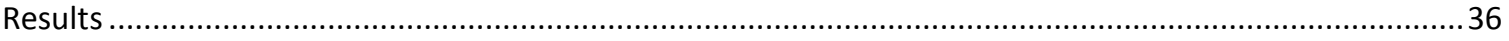

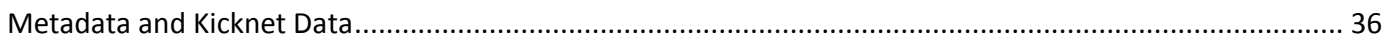

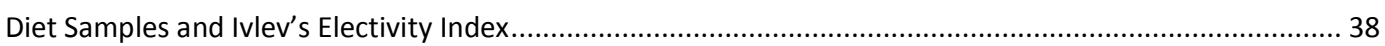

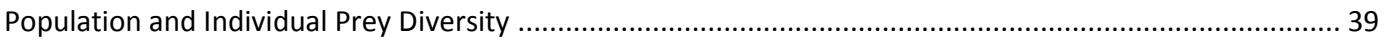

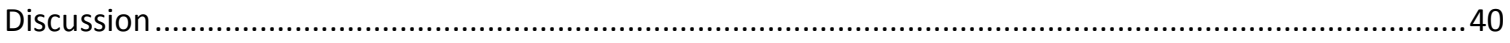

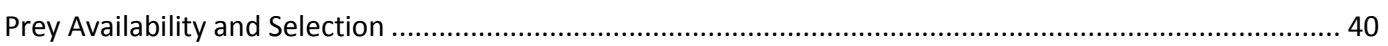

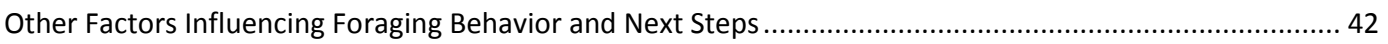

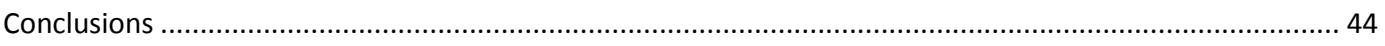

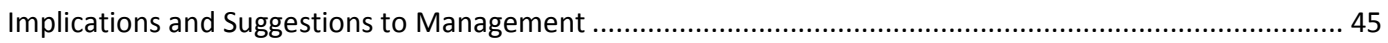

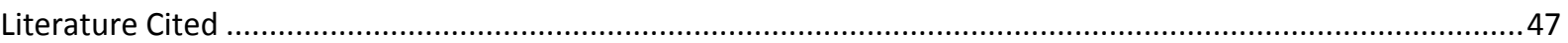

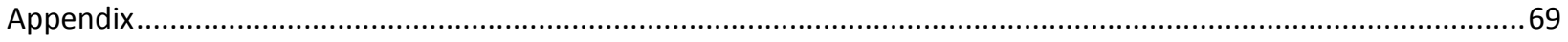




\section{List of Figures}

Figure 2.1. Map showing the location of headwater streams sampled for this study. The lowerorder stream pair is depicted by the black circles and the higher-order stream pair is depicted by the black triangles. All headwater streams were contained in the Monongahela National Forest, West Virginia, depicted in gray

Figure 2.2. Dry mass (mg) of aquatic prey (a) collected via kicknet sampling for each stream. Large prey items, including Urodela and one large Decapoda, were removed to prevent bias. Aquatic prey density (\#/m2) (b) collected via kicknet sampling (no prey items removed from analysis). Spring is depicted in dark blue and summer in light blue. Error bars represent standard error of the means. Density of aquatic prey appeared to decrease in the smaller order streams, and increased in the larger order streams from spring to summer; Although, only significance occurred in Poca Run and Crooked Fork (t-test, $p=0.025, p=0.027$, respectively). After aquatic dry mass obtained from the kicknet samples had been log-transformed to confirm normality, a two-way ANOVA for season, stream, stream $X$ season interaction with nested time of day was performed in program R. Significant difference occurred between streams $(F(3,16)=$ 4.651, $p=0.016)$ and between seasons $(F(1,16)=4.720, p=0.045)$, but not with a stream by season interaction $(F(3,16)=0.141, p=0.93)$ nor for sampling periods within the same day $(F(4,16)=1.182, p=0.36)$. Based on these results, aquatic dry mass ( $\mathrm{mg}$ ) for time of day and samples within the same season were pooled. Across individual streams, dry mass appears to decrease from spring to summer, though individual t-tests did not demonstrate significance due to low sample sizes.

Figure 2.3. The proportion of aquatic macroinvertebrates present in each diet, averaged within streams for each season. Spring is depicted in dark blue and summer in light blue. Error bars represent standard error of the means. No differences in mean proportion of aquatic prey dry weight existed in diet samples between time of day (noon versus evening) in all streams and seasons except in the first summer samples in Poca Run (Mann Whitney U Test, $p=0.021$ ). No differences in mean proportion of aquatic prey dry weight existed between diet samples within the same season, pooled across time of day, in all streams and seasons except spring samples in Poca Run, and summer samples in Whites (Mann Whitney U Test, $p$-value $=0.033, p=0.012$, respectively). Therefore, all diets within the same season were pooled. Beta regression showed no significance was found in Little Branch or Crooked Fork ( $p=0.11, p=0.28$, respectively), However, both Poca and Whites Runs' aquatic prey proportions were significantly different from all other streams ( $p<0.001$ for each). As spring progressed into summer, Crooked Fork's aquatic proportions increased while Little Branch, Poca Run and Whites Run decreased as, but significance only occurred in Poca and Whites run (interaction with sampling date, $p=0.0039$, $p<0.001, p=0.22, p=0.44$, for Poca Run, Whites Run, Little Branch and Crooked Fork, respectively). 
Figure 2.4. Results of Ivlev's Selectivity Index for Crooked Fork in spring and summer showing selection of a variety of aquatic prey categories based on abundance. Negative values indicate avoidance of prey item, positive values indicate selection and zero means neither avoidance nor selection. However, the more likely is the prey item is not found in the diets or kicknet samples. .55

Figure 2.5.Results of Ivlev's Selectivity Index for Whites Run in spring and summer showing selection of aquatic prey categories based on abundance. Negative values indicate avoidance of prey item, positive values indicate selection and zero means neither avoidance nor selection. However, the more likely is the prey item is not found in the diets or kicknet samples. .56

Figure 2.6. Results of Ivlev's Selectivity Index for Little Branch in spring and summer showing selection of aquatic prey categories based on abundance. Negative values indicate avoidance of prey item, positive values indicate selection and zero means neither avoidance nor selection. However, the more likely is the prey item is not found in the diets or kicknet samples.... .57

Figure 2.7. Results of Ivlev's Selectivity Index for Poca Run in spring and summer showing selection of aquatic prey categories based on abundance. Negative values indicate avoidance of prey item, positive values indicate selection and zero means neither avoidance nor selection. However, the more likely is the prey item is not found in the diets or kicknet samples.

Figure 2.8. Individual fish length versus average body length of all prey items contained within each stomach content sample of all Brook Trout across all streams and both seasons. A general trend of larger fish selecting larger prey is evident (slope $=0.016, R^{2}=0.057, p<0.001$ ); trout may not be more size selective in spring versus summer (spring slope $=0.017, R^{2}=0.069, p<0.001$; summer slope $=0.015, R^{2}=0.037, p=0.013$ ), which was not statistically significant (ANCOVA $p$ value for interaction $=0.64$, in program JMP).

Figure 2.9. Individual fish length compared against the average body length of all prey items contained within each stomach content sample of all Brook Trout across all streams and both seasons for aquatic and terrestrial prey. A general trend of larger fish selecting larger prey is evident (slope $=0.016, \mathrm{R}^{2}=0.057, \mathrm{p}=2.9$.e-05 Trout are more selective of aquatic prey (slope= $0.028, R^{2}=0.076, p<0.001$ ) versus terrestrial prey (slope $=0.0095, R^{2}=0.012, p=0.047$ ), which was statistically significant (ANCOVA $p$-value for interaction $=0.017$, in program JMP).

Figure 2.10. Histograms represented the frequency of diets (individual fish) with a certain proportion aquatic biomass for Crooked Fork across two seasons. Beta regression showed Crooked Fork did not significantly differ from all other streams nor with an interaction with season $(p=0.28$, interaction with season $p=0.44)$. 
Figure 2.11. Histograms represented the frequency of diets (individual fish) with a certain proportion aquatic biomass for Whites Run across two seasons. Beta regression showed Whites Run was significantly different from all other streams as well as with an interaction with season

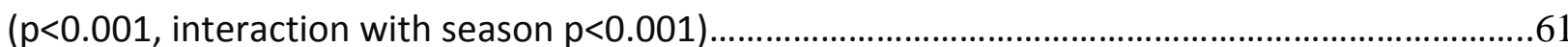

Figure 2.12. . Histograms represented the frequency of diets (individual fish) with a certain proportion aquatic biomass for Little Branch across two seasons. Beta regression showed Little Branch did not significantly differ from all other streams nor with an interaction with season

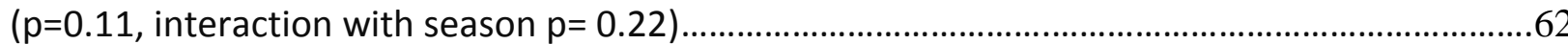

Figure 2.13. Histograms represented the frequency of diets (individual fish) with a certain proportion aquatic biomass for Poca Run across two seasons. Beta regression showed Poca Run was significantly different from all other streams as well as with an interaction with season $(p<0.001$, interaction with season $\mathrm{p}=0.0039$ ) 


\section{List of Tables}

Table 2.1. Watershed data for the streams selected and paired based on the drainage area and historical aquatic insect abundance category is presented below. Abundance of aquatic invertebrates a priori was derived from unpublished data (J. Stolarski) using a Surber sampler during spring 2006. Here, large-low refers to large drainage size and low abundance of aquatic invertebrates specifically insects. Large-high refers to large drainage area and high insect abundance, etc.

Table 2.2. Metadata collected on study streams; Average \% canopy cover was acquired via densiometer; Average aquatic prey density, biomass, and individual mass was acquired via kicknet sampling. Large prey items such as Urodela and one large Decapoda was removed to prevent bias for average aquatic prey biomass, and average individual aquatic prey mass only.

Table 2.3. Average total lengths including ranges of Brook Trout captured are presented below, along with density measurements from triple-pass electro-shocking sampling from fall 2013 . No significant differences in average fish total lengths between seasons for each stream occurred. However, each stream-order pair had significant differences in fish total length averaged across seasons; Whites Run's average $(167.2 \mathrm{~mm})$ was significantly higher than Crooked Fork's average (129.5 mm, p <0.001), as well as Poca Run's average $(163.3 \mathrm{~mm})$ was significantly higher than Little Branch's average (119.1 mm, $p<0.001)$.

Table 2.4. Results of Diet Indices in Crooked Fork- across spring and summer for the 13 most common prey groups. MNi and MWi refer to mean proportion by number and weight (displayed as percentage), respectively, for each prey. Oi and \%IRI refer to frequency of occurrence and percent index of relative importance for each prey type i.....

Table 2.5. Results of Diet Indices in Whites Run across spring and summer for the 13 most common prey groups. MNi and MWi refer to mean proportion by number and weight (displayed as percentage), respectively, for each prey. Oi and \%IRI refer to frequency of occurrence and percent index of relative importance for each prey type i....

Table 2.6. Results of Diet Indices in Little Branch across spring and summer for the 13 most common prey groups. MNi and MWi refer to mean proportion by number and weight (displayed as percentage), respectively, for each prey. Oi and \%IRI refer to frequency of occurrence and percent index of relative importance for each prey type i....

Table 2.7. Results of Diet Indices in Poca Run across spring and summer for the 13 most common prey groups. MNi and MWi refer to mean proportion by number and weight (displayed as percentage), respectively, for each prey. Oi and \%IRI refer to frequency of occurrence and percent index of relative importance for each prey type i. 


\section{Chapter 1: Literature Review}

\section{Terrestrial and Aquatic Linkages via Headwater Streams}

The physical boundaries of two ecosystems may be distinct (i.e. terrestrial and aquatic), but the exchange of biological material can have profound impacts on biotic communities in each system (Polis \& Hurd, 1996). For example, highly productive marine coastal waters (due to upwelling, high light penetration and other factors) contribute energy to the local terrestrial ecosystem via direct routes such as algal or dead sea organism drift or indirectly through seabirds which feed on marine life and transport energy to land in feces (Polis \& Hurd, 1996; Polis et al. 1997). These processes may lead to one ecosystem receiving more energy than donating; and therefore certain materials are considered 'subsidies' from the adjacent ecosystem (Baxter et al. 2005). In headwater riparian areas, huge pulses of emerging aquatic insects are delivered directly to spiders and birds (Baxter et al. 2005; Kraus et al. 2016); however, riparian vegetation greatly subsidizes adjacent streams, in the form of leaf litter and terrestrial invertebrates (Baxter et al. 2005; Polis et al. 1997). The biological communities in these head water streams utilize these subsidies which add to expected trends as described by the River Continuum Concept (RCC) (Vannote et al. 1980).

The RCC denotes certain predictable gradual trends in the biological communities at the reach scale within a watershed are expected to occur due to physical attributes such as stream size, gradient, terrestrial inputs and light penetration (Vannote et al. 1980). This paradigm specifically applies to the macroinvertebrate feeding guilds and those fish whom prey upon them. The RCC has been both supported and challenged (Ward, 1986; Townsend \& Hildrew, 1984). Frissel et al. (1986) expanded further on this paradigm by developing the hierarchical view of stream, in which macro- and micro- habitat scales are considered. Grubaugh et al. (1996) sampled a variety of microhabitats (riffles, pools, depositional areas) and substrates (bedrock, cobble, sand) along a continuum in southern Appalachia. The macroinvertebrates present followed the RCC, but certain microhabitats, e.g. riffles, seem to disrupt these predictable trends (Grubaugh et al. 1996).

Headwater streams have a suite of characteristics that set them apart from the rest of the watershed. They consist of pool-riffle sequence due to slopes being greater than $2 \%$ 
(Hubert \& Quist, 2010). Low water temperatures are provided by groundwater, as in the Appalachian Mountains, or snowmelt. Temperature is further regulated by tree canopy cover due the high water edge to water surface area (P/A) relationship (Polis et al. 1997). The canopy cover limits light penetration to the streambed reducing primary production (autochthonous materials), causing low fish and macroinvertebrate abundance. A large amount of terrestrial biomass (allochthonous material) enters the stream. Leaf litter and other biological material create coarse particulate organic matter (CPOM), > $1 \mathrm{~mm}$, which is utilized by specialized benthic invertebrates also known as "Shredders" (Vannote et al. 1980). These subsidies can have positive bottom-up effects in the food web (Baxter et al. 2005). Much research has been devoted to the effects of leaf litter to the subsidizing of local aquatic invertebrates in headwater streams (Vannote et al. 1980). More recently, attention has been paid to terrestrial invertebrate (hereafter denoted as $\mathrm{Tl}^{\prime} \mathrm{s}$ ) inputs to these systems. This possibly due to the fact that TI's are readily available to predatory fish (Mason \& MacDonald, 1982). In North America, these fish species are in the Salmonidae, Percidae, Cottidae, and Cyprinidae families (Hubert \& Quist, 2010).

TI inputs to headwater streams can have direct and indirect effects on the accepting stream community (Nakano et al. 1999b). Nakano et al. (1999b) preformed an experimental study on the Horonai stream on the northern-most island in Japan, on four stream reaches. The first reach was manipulated by having neither Tl's inputs nor any predatory fish such as Dolly Vardon (Salvelinus malma) present. The other three reaches were manipulated by having a combination of presence or absence of either variable. The presence of Tl's did not have a direct effect to the periphyton nor herbivorous arthropods in the absence of predatory fish. However, in the presence of fish, the biomass of aquatic herbivore invertebrates decreased, and incidentally increased the biomass of periphyton, thereby alleviating the trophic cascade to a possible 'trophic trickle' caused by top fish predators (Nakano et al. 1999b; Allan \& Castillo, 2007). Takimoto et al. (2002) developed a model that further demonstrates TI subsidies not only relieve some predation pressure on aquatic invertebrates, but stabilized the food web when autochthonous materials are in short supply. 
Allen (1951) was one of the first to reveal evidence on the effects of TI inputs to the local fish population. He calculated the production of Brown Trout (Salmo trutta) flesh per unit area in the Horokiwi stream in New Zealand. While utilizing laboratory data on the energy requirements for Brown Trout, Allen discovered the fish biomass was on orders of magnitude larger than what the benthic invertebrate community alone could support. Tl's contributed a significant amount in number and weight to the Brown Trout diets, and thus subsidized the trout population. This phenomenon became known as the 'Allen Paradox' (Hynes, 1970). This accepted concept launched a whole series of studies concerning $\mathrm{TI}$ inputs to streams of low primary production with relation to trout.

\section{Trends in TI Contribution to Headwater Streams}

In order to gain further insight into the abundance, biomass and fluctuations of Tl's entering headwater streams, the surrounding terrestrial environment was considered in much of the previous research. Mason and MacDonald (1982) were probably one of the first to directly measure and compare $\mathrm{TI}$ input to streams and directly beneath various tree species. In particular, they found sycamore (Platanus occidentalis) contribute more insects to the streams than other trees. They also stated that $\mathrm{TI}$ inputs to the stream are highest in the spring and summer, which is similar to what Romaniszyn et al. (2007) found. They studied invertebrate drift (i.e. prey items drifting in stream flow) in eight Appalachian mountain streams with four different riparian vegetation types. Abundance and biomass was highest during spring and early summer for $\mathrm{Tl}^{\prime}$ s, even though aquatic invertebrate (AI) abundance was higher during those seasons. On a day scale, TI drift was highest at noon and Al's at dusk. Riparian cover also produced significantly different results in terms of TI inputs; open canopies and streams adjacent to pastures had the highest TI abundances (Romaniszyn et al. 2007). Most work has been performed during summer, spring and fall when TI drift is assumed to be the highest. Ironically, Leung et al. (2009), described higher TI drift concentrations in winter than summer in a coastal, boreal-forested stream in British Columbia, which was associated with overall higher flows during that season (see next section). 
In New Hampshire, Wilson et al. (2014) sampled a range of vegetation habitats that had the propensity to influence TI contribution to Brook Trout (Salvelinus fontinalis) diets. The riparian vegetation including early succession versus late succession forests, as well as the streams proximity to patches of Early Successional Habitat (ESH) and canopy cover over stream were considered. Surprisingly, there was very little percent overlap with what was found in each of these cover types to the TI inputs to the stream and Brook Trout stomach contents (explained further in 'Research on Brook Trout and Other Trout Diets and Prey Preference' section). Similarly, Allan et al. (2003) found terrestrial invertebrate taxa differed depending on the riparian plant species they inhabit including coniferous (lower biomass) as compared to deciduous overstory and understory; however, this did not affect the biomass contained in juvenile Coho Salmon (Oncorhynchus kisutch) diets. The researchers hypothesized that homogenization of Tl's potentially occurred outside of stream (wind) and instream (water dispersal). However, Studinski and Hartman (2015) found that with 90\% basal area removal of trees in the riparian corridor, TI family composition changed and biomass increased while no difference occurred in abundance or richness. They suggested the insect communities shifted from being of forested habitat to decomposing wood and flowering plant habitat, in addition to increases in the overall individual body size. Additional studies have included different vegetation types and agricultural practices (Benstead et al. 2003; Saunders \& Fausch, 2007). It is evident that the amount, composition and importance of TI inputs is difficult to explain in general trends that can encompass all watersheds in different ecotones and be applied directly to Brook Trout production.

\section{Invertebrate Drift Related to Brook Trout}

Drift is defined as terrestrial and aquatic invertebrates that are captured and transported downstream in the water column by current, acting as food delivery system to trout (Leung et al. 2009). Invertebrate drift is very heterogeneous in terms of biomass and species composition across seasons, and day; there even can been fluctuations between days

within the same week (Brittan \& Eikeland, 1988). Higher velocity equates to higher invertebrate abundance in drift which is obvious between seasons, though not apparent at the microhabitat 
scale as demonstrated Leung et al. (2009). Velocities between pools and riffles are indeed different, but Al drift abundance does not reflect this. The researchers attributed it to the average length of a small microhabitat $(4.0 \pm 2.0 \mathrm{~m})$ being shorter than the average driftentrainment distance of an organism (3-10 meters). The small size of a headwater stream seems to homogenize the availability of drift invertebrates both at the microhabitat scale and surface/subsurface locations in the water column. This relationship may change in larger stream and river systems.

Seasonal Al drift density and biomass are lowest in summer months as emergence increases (Wipfli, 1997). Furthermore, as stream flow decreases during this time, Al become more entrained by rocky substrate; Al's also actively burrow in substrate to avoid desiccation. During the winter months, Al drift density and biomass are greatest as newly allochthonous (Autumn leaf litter) material is utilized and flows increase (Sweka \& Hartman, 2001b; Leung et al. (2009). Leung et al. (2009) also found Tl's drift abundance to be highest during winter months. This is thought to be attributed to higher flows causing water to cover previously dry banks occupied by TI's and not due to TI's accidentally falling in from tree canopy, as in summer months.

Aquatic invertebrates enter the drift either intentionally or accidentally (Rader, 1997). Accidental drift refers to nonintentional dislodgement of an organism, and should occur throughout the day and night. Al's intentionally enter the drift either to avoid predators or competition, search for resources, or avoid anoxic conditions. For the most part, $\mathrm{Al}^{\prime} \mathrm{s}$ restrict the intentional drift to twilight and night hours to avoid predators. Intentional twilight drifting is thought to be a product of Al's premature perception of darkness due to the limited light in interstitial spaces and benthic crevices as opposed to slightly more luminous conditions in the water column during those periods. During the spring and summer months, this predator avoidance behavior is apparent (Rader, 1997). However, in fall and winter months intentional drift occurs throughout the 24-hour daily cycle as demonstrated by Sweka and Hartman (2001b).

Rader (1997) classified and ranked different aquatic invertebrates in terms of their drift availability to trout. He compiled data from three studies that took place in central Rocky 
Mountains streams in Colorado. The categories he developed placed Al's, specifically insects, in new guilds (not equivalent to feeding guilds) based on intentional drift propensity, habitat, flow exposure, drag index, adult drift, benthic exposure, size and abundance. Spearman's Rank correlation between trout stomach contents and these new guild rankings showed high correlation; meaning aquatic insect genera with higher drift availability to trout were more present in the diets. This study demonstrates not all Al's are equally available to trout, i.e. burrowing ephemerids are not highly accessible due to occupying the hyperopic zone, better swimmers such as amphipods and baetids can evade predators more easily than other genera and better crawlers, such as heptageniids, can avoid entering the drift altogether. Therefore, generic Al presence and abundance does not equate to high trout production (Rader, 1997).

\section{Brook Trout in Central Appalachia}

Brook Trout are native charr to the Eastern United States and have evolved in cool, clear streams. They serve as an indicator species, and their absence in certain streams signifies impairment (Trout Unlimited, 2006). In headwater streams, they have a three year-life span, maturing at year two and are iteroparous, though repeat spawning is rare (Jenkins \& Burkhead, 1993). Age at sexual maturity can vary within a population, subpopulation, and even within the same stream (Hubert \& Quist, 2010). Seasonally, Brook Trout have higher energetic requirements in the spring and summer months due to higher gastric evacuation rates associated with higher water temperature and lower in the fall and winter (Willers, 1981). Coincidentally, summer provides the least amount of aquatic prey items and winter the most (Wipfli, 1997; Sweka \& Hartman, 2001b).

Due to the different resource requirements in several life stages of riverine trout, potamodromy, out of natal streams is often necessary (Hubert \& Quist, 2010). Brook Trout populations in central Appalachia fall under the 'dynamic landscape' paradigm in which fish movement is attributed to habitat patchiness as well as differential use of critical habitat (i.e. reproduction versus foraging) (Fausch et al. 2002). This is apparent across seasons in which variable aquatic production occurs. Headwater streams are preferred by juvenile and young adult Brook Trout due to a number of physical and chemical attributes including cold water temperatures and High alkalinity (>10 mg CaCo3/L) (Petty et al. 2005). The reduction of 
seasonally high flow events, aside from storms, makes headwater streams ideal for egg incubation. Competition and predation are greatly reduced in these areas as well. Movement out of headwater streams, especially by larger adults, is primarily due to limited foraging resources. Older adult Brook Trout tend to emigrate to larger-order streams in spring and summer in which macroinvertebrates provide the necessary biomass to meet their daily ration and move back into natal streams during fall spawning times (Petty et al. 2005). Of the remaining younger individuals, most appear to be sedentary (home ranges between $301 \mathrm{~m}$ and $637 \mathrm{~m}$ ) in the springtime when headwater streams are most productive, with a small portion of the population moving greater distances (>900m) (Hartman \& Logan, 2010; Hansbarger et al. 2010). Variable movement in summer is said to occur, but may be a function of higher discharge rates (Hartman \& Logan, 2010). Brook Trout movement may be attributed to success of social learning, allowing them to quickly recognize prey resources in a new environment (White \& Gowan, 2014).

\section{Trout Physiology, Feeding and Position Choice}

Salmonids and trout are considered opportunistic generalist feeders, utilizing prey drifting on the water surface (TI's), within the water column (TI's and aquatic invertebrates) as well as benthic invertebrates (Hynes, 1970). More recent research suggest they may utilize benthos up to $40 \%$ in the winter, although some bias may exist due to the fact that benthic Trichoptera with cases in addition to Taeniopterygidae (the main prey source during this time) may take longer to digest (Sweka \& Hartman, 2001b). It was first established that these fish select prey in proportion to their abundance in the environment (Allan 1981). However, recent research may suggest more complex mechanisms are at work and preferences towards certain prey occur (Hynes, 1970). Trout learning must also be considered; Allan (1981) and McLaughlin \& Grant (1994) suggested trout may exhibit 'training bias' towards organisms they encounter more often due to prey items' temporal and spatial patchiness. Ontogenetic shifts occur as well, tout have the propensity to become more selective as they age as well as switch from insectivory to piscivory (Hubert \& Quist, 2010). With respect to territoriality, Brook Trout display a range of aggressive behaviors, which makes it difficult when understanding economic defendability or the trade-off of energy spent defending a territory versus the amount of 
energy taken in (i.e. Optimal Foraging Theory) (Grant \& Noakes, 1988). Visibility of a prey item and the perception by a trout must first be addressed (Zeret, 1980; Grubbs, 2003).

\section{Perception}

Perception of a prey item from the view point of a Brook Trout involves better understanding their sensory systems (Grubbs, 2003). Due to the attenuation of light in water as well as diffraction, salmonids are equipped to detect UV light and polarized light. These attributes help aid in detection of prey items in addition to better understanding their environment. Al's have combatted this with crypsis, the evolution of a color pattern matching its environment in order to evade predators. In a laboratory setting, Johnsson \& KjällmanEriksson (2008) found the time it took Brown Trouts' (Salmo trutta) learned detection of a conspicuous prey was faster than inconspicuous prey based on background color. Mechanical perception through the lateral line and inner ear allow salmonids to detect vibration from their environment (Grubbs, 2003). Larger, more conspicuous prey such as many $\mathrm{Tl}^{\prime}$, are an easy target for trout. These organisms generally lack crypsis and produce a lot of vibration from the jerking, struggling motion they exhibit when hitting the waters surface (Zaret, 1980). Smell and taste also aid in prey detection, though these sensory systems may not be under as complex evolutionary selection as visional and mechanical perception may be.

The process of food acquisition generally follows the pattern of search, encounter, orient, follow, pursue, strike, attack, capture and finally ingest prey (Guy \& Brown 2007). Mistakes and mishaps can be made at any point along this path that will allow a prey to not be 'selected' for, making it difficult to understand preference in a field setting, when direct behaviors are not observed. Signal Detection Theory allows for better understanding of detection of a prey item (Grubbs, 2003). A trout may not have perfect knowledge of its habitat and must distinguish between the background 'noise' of its environment and the 'signal' that is a prey item. This relationship can vary depending on the light of the environment and false detections can occur. In this case, evolution would push a species to maximize correct detection. However, there is a tradeoff between correct detection and correct rejection; both cannot be maximized. Light very much influences this relationship, which may be why trout 
prey acquisition is reduced with reduced light levels i.e. decreased sunlight or increased turbidity levels (Sweka \& Hartman, 2001a). Additionally, Snell's window (Grubbs, 2003) affect how a TI is perceived. This is the window in which fish can see through to the terrestrial world, anything outside of the circle is a reflection of the stream bed. Fish will only be able to detect prey items at the surface when it is within this window; detection outside of this window potentially occurs when the prey item breaks through the surface tension most likely with their appendages.

The Reactive Distance (RD) is used to describe the distance at which a prey item is detected (Dunbrack \& Dill, 1984). This is a direct positive correlation between prey size and reactive distance and has been shown to be associated to actual size of prey captured. Dunbrack and Dill (1984) explained that this RD is only on one plane from the fish's perspective and may be helpful when described sit-and-waiters such as Bluegill (Lepomis macrochirus); however, cruisers' (in a lentic system) or drift foragers' (in a lotic system) feeding patterns may best be explained by a three-dimensional view. This view encompasses the plane above (surface feeding), in front of (planktonic for lacustrine species, and drift feeding for riverine species) and below (benthic feeding) (Gregory \& Northcote, 1993). The forage rates of each of these planes decreases with increased turbidity for juvenile Chinook Salmon (Oncorhynchus tshawytscha) under laboratory conditions as demonstrated by Gregory and Northcote (1993). In addition, forage rates remained low for benthic and surface feeding as compared to planktonic feeding, suggesting that they may be avoiding predators in the water column when in clear water.

\section{Learning}

Distinguishing between edible and nonedible prey items is a learned behavior (Willers, 1981). Often many mistakes are made in newly emerged fry, but within a few weeks they begin to decipher prey items. However, before a novel prey item is actually utilized, a Search Image must be developed (White \& Gowan, 2014). This involves predator encountering and recognizing the prey item often enough before it can display a foraging preference toward it Trout can have 'training bias' towards a particular prey item they have encountered previously 
(Dill, 1983). In fact, this can lead to specialization by different individuals within the same population, and more importantly, demonstrating different adaptive peaks (Willers, 1981). Brook Trout have been known to show a preference even towards certain life stages (i.e. naiads of Plecoptera and Ephemeroptera) even though other aquatic prey were available (Dave Throne, WVDNR, personal communication, Jan. $\left.25^{\text {th }}, 2016\right)$. This can be fleeting however as feeding resources are constantly being shifted (Willers, 1981).

Social learning aids in the acquisition of a search image of a naive Brook Trout immigrating and inserting itself into the dominance hierarchy in a new stream faster than social learning would (White \& Gowan, 2014). This partly contributes to the success of Brook Trout in a patchy (temporally and spatially) environment, in which prey items can be fleeting. Furthermore, in this experiment (White \& Gowan, 2014) which used wild Brook Trout, the demonstrators (fish that were exposed to meal worms prior to being released to naïve individuals) possibly developed a search image not only for meal worms, but for an association to prey items being released near the feeder (surface or subsurface). The researchers never saw fish foraging on the meal worms in the benthic portion of the experimental tanks. Thus fish search images may involve not only recognizing the prey items themselves, but the location in the water column.

\section{Hunger level}

A fish's hunger level is also tied to selection of prey; it has been demonstrated experimentally that as a fish becomes more satiated during a feeding period they tend to handle their prey more and become more selective and avoid novel prey (Willers 1981). They have a larger diet breath when near starvation, incorporating less ideal prey. A fish can estimate food availability via stomach fullness signals as indicated by its hunger level (Dill, 1983). Additionally, when prey densities are low, trout tend to select larger prey, due to a longer reactive distance, which has been shown experimentally (Willers 1981). Dill (1983) stated starvation may lead to more generalist feeding behavior whereas continual encounter of the same prey item leads to training bias and ultimately specialization. Trout ultimately have 
adaptive flexibility in their foraging behaviors depending on the current environmental circumstance (Dill, 1983).

Stomach fullness may have foraging behavioral applications. Piccolo et al. (2014) summarized an anomaly discovered by Hayes et al. (2000) in which drift feeding fish were able to maximize their daily consumption when stomach fullness was not reached; if the stomachs were not full, digestion and feeding could occur simultaneously. Thereby if satiation did not occur (either from high turbidity, low abundance) and digestion was high (due to higher water temperatures) over time, more prey or energy could be consumed and time was not wasted digesting when just satiated (i.e. no feeding occurring).

\section{Polymorphism and Behavioral Plasticity}

Prey selection is tied to physical attributes of the environment i.e. water velocity (Proulx \& Magnan, 2004). In a lentic system, trophic polymorphism and plasticity were observed between Brook Trout feeding on littoral versus pelagic sources. Swimming features for either environment such as pectoral and dorsal fin sizes and lengths were considered genetically controlled (polymorphism) whereas feeding features such as lower jaw length were affected by the environment (phenotypic plasticity). This feature changed as individuals from one environment were switched to another such that fish placed in the pelagic feeding environment grew longer lower jaws to accommodate for more mobile prey. This research suggests Brook Trout have the capability to adapt to different feeding tactics in the presence of alternate prey over the course a very short time frame (in this study four months) (Proulx \& Magnan, 2004).

Though using morphological polymorphism as a way to describe the prey choice of Brook Trout in a lentic setting is very applicable; in a lotic system, body morphology and polymorphism is more a product of water current and indirectly from prey selection. McLaughlin \& Grant (1994) studied body morphology in comparison with habitat and prey selection in a watershed in Ontario, Canada in juvenile Brook Trout. Individuals found in faster water current displayed a more fusiform body type with a larger caudal fin relative to a smaller caudal peduncle. These individuals also selected prey in the middle of the water column versus water surface or benthic, presumably because there is an energetic trade-off between spending 
more energy swimming in these environments and less on prey foraging. They suggested terrestrial prey found at the surface tend to be more chitinous and take longer to digest as well, giving more rationale as to why juvenile Brook Trout eat more Diptera larva found within the water column.

Juvenile trout in streams may exhibit some polymorphism associated with feeding. For instance, McLaughlin et al. (1999) described two alternative foraging tactics, the sit-and-wait or active searching tactics, in YOY Brook Trout. Later research by Wilson and McLaughlin (2010) demonstrated that the size of the telencephalon (a part of the brain associated with movement and space) varied in YOY Brook Trout in still pools near streamside. The size differences were associated with different feeding tactics in which individuals with larger telencephalon were actively searching for insects near the surface versus those with a smaller telencephalon used the sit-and-wait tactic mostly searching for crustaceans and insect emerging from the hyporheic zone. These tactics could be prerequisites for feeding polymorphisms in adults or more probable, different behavioral plasticities that are not fixed (McLaughlin et al. 1999).

Alternative foraging tactics may emerge in juvenile and adult trout due to the utilization of different microhabitats. Different velocities associated with changing microhabitats (e.g. pools to riffles) concentrate resources and alter energy intake and growth of a drift forager (Giller \& Greenberg, 2015; Gustafsson et al. 2014). Giller \& Greenberg (2015) identified two types of feeding tactics, 'movers' and 'stayers', in a Brown Trout stream population in Sweden via diet analysis and PIT tagging. Stayers of a pool habitat generally had more terrestrials and overall diversity in their diets as comparted to stayers of riffle habitat. Stayers of riffle habitats ingested more aquatic invertebrates and had an overall higher abundance of prey, but that could be attributed to the smaller size of prey and higher velocities. Movers had a more intermediate diet due to moving between riffle and pool habitats. They may never enter a dominance hierarchy. Their growth rate was lower than those that stayed in pools presumably due to the higher energetic cost of movement. Though there was no direct evidence of specialist versus generalist feeding tactics, it is clear that members of the same population are using different habitats or foraging tactics to obtain prey. Furthermore, Gustafsson et al. (2014) demonstrated that the introduction of large woody debris can also increase growth in Brown 
Trout by increasing habitat heterogeneity (i.e. depth and velocity) in stream. This also increased refugia for trout while having adjacent access to high velocity (or high aquatic drift abundance) allowing it to maximize its NEI (Net Energy Intake). Ultimately, fish biomass, and density increased with increased LWD (Large Woody Debris); however, Al's did not seem to benefit from these inputs as previously thought due to habitat increase.

\section{Territories}

Trout, especially juveniles, in streams develop individual territories to defend food resources (Willers, 1981). The territory size is proportional to the fish size; For example, Atlantic Salmon (Salmo salar) fry may have a territory of $76.2-127 \mathrm{~cm}^{2}$ while a $22.86 \mathrm{~cm}$ Brown Trout has $3.34451 \mathrm{~m}^{2}$. The territory involves choosing a stationary point, adjacent to some cover, usually within a select distance of a visual object (log or rock) used as a reference. The individual orients itself to the direction of on-coming current to capture prey items in the drift. After the individual pursues prey or chases a conspecific it will return to the same stationary point in its territory (Willers, 1981). Interestingly, territories are only present when there is current. In the absence of current, larger individual trout tend to show irregular swimming patterns and smaller individuals school (Willers, 1981).

As fish grow, their need for energy increases; territories eventually become too large, overlap and diminish (Willers, 1981). These larger fish move into locations within the stream better suited for drift feeding to establish a more complicated set of territories known as the dominance hierarchy. This involves a 'pecking order' in which the most dominant trout (usually largest) occupies the most ideal spot for drift foraging while also being near desirable cover. The next most dominant individual occupies the $2^{\text {nd }}$ most desirable spot, and so on. However, this is a fluid relationship; the most dominant is often challenged by subordinates, and the next most dominant is ready to take its place. Furthermore, stragglers that frequently move, constantly challenge the order. Dominance Hierarchies are not very stable on the individual level but continue to exists as long as drifting prey are available (Willers, 1981). In fact, trout tend to leave dominance hierarchies to enter more open pools in the evenings to access flying insects (Willers, 1981). 
Feeding is highest during morning and evenings. Though it has been highly supported that Brook Trout are diurnal feeders, Forrester et al. (1994) documented some feeding occurs at night. Brook Trout ingest much less biomass during this time and are less size and taxa selective as compared to daytime, aside from abnormal weather events or during period of full or nearly full moon.

\section{Optimal Foraging Theory}

The Optimal Foraging Theory (OFT) can be applied to stream dwelling trout in order to predict and better understand their prey preference. The basic premise of this theory is this: an extant species is under selective pressure and should live optimally in its environment in order to achieve the highest fitness. By those accounts, foraging behavior should be under selective pressure as well (Pierce \& Ollason, 1987; Pyke et al. 1977; Sinervo, 1997). However, defining how an animal feeds "optimally" is quite complicated and involves using an economic modeling perspective and applying the idea of currency to prey items. An animal foraging optimally has to make quick decisions on the available prey (Sinervo, 1997). This means weighing the energetic cost of pursuing and capturing prey versus the energetic value of the prey item. For any given species, they may be limited by time, energy, and cognitive abilities (learning and memory). Size of prey item is probably the best measure of its worth to a predator; larger prey usually indicates more energy pay off (Sinervo, 1997). This size selection has been observed in trout (Rader, 1997; Sweka \& Hartman, 2001b); as they continue to grow they incorporate larger prey items while still utilizing smaller prey items. However, Rader (1997) proposed that an increase in handling time makes ingesting a prey not worth the energy gained versus energy expended. For a $20.0-30.0 \mathrm{~cm}$ fish, prey reaching $10.0-20.0 \mathrm{~mm}$ become too cumbersome. Too much energy expending on handling (i.e. jerking head side to side to properly chew and swallow) must also be assessed by the individual trout (Willers, 1981).

The OFT has been demonstrated in birds (oystercatchers, African seed-crackers) in which one or two optimal foraging strategies designated by the Optimal Foraging Rule are used which encompasses a trade-off between energy acquired (seed or mussel size) with the energetic cost of handing (breaking open mussels or seeds, larger equates to more energy exerted) (Sinervo, 1997). In Bluegill, it has been experimentally shown that they utilize all sizes 
of prey (Daphnia magna) equally at low densities; as densities increase, these fish become more size selective. The researchers suggested Bluegill balanced the encounter rates of prey (time) and handling time with the energetic costs of the prey item (Werner \& Hall, 1974). Other theories have been built upon the OFT, such as the Marginal Value Theorem (Charnov 1976), which allows the "giving-up time" or time it takes an animal to leave a current area of resources in search of another area in a patchy environment to be estimated. This Theorem can certainly be applied to larger Brook Trout leaving a headwater stream in the summer, when drift concentrations can no longer meet their daily ration.

There have been criticisms of the applicability of the OFT (Pierce \& Ollason, 1987). The main being, the animal has to have a complete knowledge and ability to predict all the resources available to it. Clearly this is impossible, which is why the Signal Detection Theory has been employed; however, the ways in which an animal learns and records information about its environment can still be used 'optimally' (Pierce \& Ollason, 1987; Sinervo, 1997). A search image often needs to be developed for cryptic and novel prey prior to the utilization of that prey. Another criticism is most optimal foraging models are of a static environment and do not encompass changing situations (Dill, 1983). All in all, predicting or modeling behavior of a trout operating under the OFT should encompass handling-time and capture efficiency of prey, size and view of prey, learning capabilities of predator, physical challenges in the environment, light and turbidity, velocity and depth of water, and the hunger state of the predator (Werner \& Hall, 1974).

Depending on the type of feeding, e.g. omnivory, planktivory, piscivory, etc., the costliest attribute of foraging could be different. For instance, with plankitvores, handling time is generally low, making prey encounter rates the main factor limiting prey ingestion. This translates to a correlation between these fishes being able to be more size selective, especially at high densities. In pisicory or onmivory feeding strategies, this relationship is not as strong due to the higher cost associated with handling and searching time (i.e. low encounter rates); switching to defending a territory in order to gain access to drifting prey is more feasible (Guy \& Brown, 2007). 
While operating under the OFT, drift foraging models were developed to predict a fish's position in stream in association with the energy costs (Piccolo et al. 2014). The idea being that the individual picks a position to maximize growth. This involves quantifying both prey abundance and the physical habitat in terms of velocity and depth to understand how salmonids select a habitat (Rosenfeld et al. 2014). For the most part, this stems from the driftfeeding theory developed by Fausch (2014). The Net Energy Intake (NEI) is found by calculating the trade-off of swimming costs to the energy gained from prey. Several variables based on a fish's surroundings and its focal point are incorporated into the model. From this, the Gross Energy Intake (GEI) can be calculated and the swimming costs can be subtracted from that to get NEI (Hughes \& Dill, 1990). As velocity increases, so do the abundance of drifting prey items; however, there is an energy cost associated with swimming or maintaining positions that increases with velocities. Additionally, velocity can reach a point that it is too fast for a trout to capitalize on all the prey item drifting by. Therefore, there is an ideal velocity in which $\mathrm{NEI}$ is maximized (Grubb, 2003). Piccolo et al. (2014) demonstrated that a fish maximizes its NEI by positioning itself facing up stream in slow current alongside faster current in order to capture prey.

Later models on Arctic Grayling (Thymallus arcticus) incorporated more than one individual to demonstrate dominance hierarchies (Hughes 1992). Similar to the single individual models, the NEI was based on physical attributes and prey abundances, but another component was added in which position choice was also dependent upon the positions of other individuals. The model predicts the best position possible for an individual in a dominance hierarchy based on its ability to defend that position and access its own 'foraging window'. Water temperature has also been incorporated into these models due its effect on metabolism; when food is scarce, Hughes (1998) proposed the largest Artic Grayling will be present in colder temperatures, higher up in a stream to reduce energetic cost. If food is plentiful, larger individuals will occupy warmer parts of the stream or watershed to capitalize on prey by attaining a higher metabolism. Although these models have limited verification (Piccolo et al. 2014) they may have a place when determining why Brook Trout seem to prefer aquatic invertebrates over terrestrial invertebrates. 


\section{Research on Brook and Other Trout Diets and Prey Preference}

Many studies concluded that anywhere from $40-50 \%$ of trout diets consisted of $\mathrm{Tl}^{\prime} \mathrm{s}$ (Hynes, 1970). Results from a study by Cada et al. (1987) demonstrated 45 and $50 \%$ of diets in Rainbow Trout (Oncorhynchus mykiss) and Brown Trout, respectively, are composed of Tl's. Utz and Hartman (2006) demonstrated through a bioenergetics study in Appalachia, the importance of terrestrial invertebrate inputs to Brook Trout's summer survival. Hartman and Sweka (2008) studied the bioenergetic requirements for Brook Trout year-round in headwater streams in the Middle Fork watershed of the Tygart River in West Virginia. The energy contained in the stomach contents were compared to investigate which individual fish were feeding above or below their daily energy quota or maintenance ration. Further statistics were used to analyze if different prey sources (terrestrial and aquatic) contributed to the fish meeting its maintenance ration. The results revealed that, except for winter months, Brook Trout rely heavily on large terrestrial invertebrates, such as Coleoptera and Lepidoptera, to fill their daily energy requirement. This study also raised awareness that prey cannot be simply categorized as terrestrial or aquatic, but need to be further separated out taxonomically. Though support for the idea that Brook Trout feed selectivity could not be implied from this paper, it reiterated the reliance Brook Trout have on large, but infrequent prey items.

Allan (1981) studied Brook Trout feeding behavior in Cement Creek, in western Colorado. His results showed strong Spearman's correlations between the amount of prey found in drift and benthic samples and the prey items found in fish diets based on percent composition. Even though there were few outliners (mainly large Tl's) Allen suggested Brook Trout are simply selecting prey based mainly on the abundance, then size, then learned detection for certain prey (Allan, 1981). This is quite a different system (this study took place in a high elevation meadow, with some riparian vegetation consisting of Salix spp.) than Appalachian streams from which Brook Trout are native, where it has been shown that trout depend more on large $\mathrm{Tl}$ input.

Niles (2010) suggested Brook Trout exhibit generalist and opportunistic feeding behaviors when exposed to different riparian vegetation management practices (i.e. feeding on large $\mathrm{Tl}^{\prime} \mathrm{s}$ when aquatic invertebrates were limited). However, in areas producing sufficient 
autochthonous materials (areas with 90\% open canopy), Brook Trout selectively fed on aquatic invertebrates even though large Tl's were available. This suggests a preference towards aquatic invertebrates. Wilson et al. (2013) showed similar trends. Although most variables sampled did not have a direct relationship to TI inputs, the amount of aquatic invertebrates available in the stream had a significant negative relationship to Tl's percentage found in diets. The higher amount of aquatic invertebrates available the lower the percentage of Tl's in the diet, regardless of the amount of $\mathrm{Tl}$ inputs, again suggesting a preference towards aquatic invertebrates.

Other trout research would suggest a preference towards Al's. Nakano et al. (1999a) proposed Rainbow Trout in headwater streams in Japan actively select TI's in drift due to their diets being comprised of 77\% Tl's. Eros et al. (2012) experimentally reduced terrestrial input and increased light to boreal coniferous-forested streams. They did not see an ontogenetic difference in stomach contents which has been shown previously by other researchers. However, they did find that Brown Trout in experimentally reduced TI's reaches had lower growth rates in the summer than trout in reaches without reductions. This may suggest the trout did not utilize the Al's available due to aquatic production being insufficient to support growth, so they demonstrated a preference towards TI's. As mentioned previously, Cada et al. (1987) demonstrated a similar preference in both rainbow and Brown Trout in an Appalachian ecosystem. Higher percentages of TI's in the diets of both species occurred than the percentage available in the environment.

It might be possible that a predator switching from Al to TI or vice versa to forage opportunistically was not captured in these previous scenarios thereby giving the illusion of preference because not enough time elapsed. Predator "switching" has been experimentally demonstrated with invertebrate predator/prey relationships in which the depletion of one type of prey causes the predator to switch to an alternative prey, thereby allowing the first prey population to recover (Murdoch, 1969). These behaviors may not be as obvious in stream trout, but the switching of foraging tactics has been documented experimentally by Fausch et al. (1997). Two charr (Salvelinus malma and S. leucomaenis) in a Japan mountain stream shifted feeding tactics when living sympatrically to partition their foraging resources. However, 
Courtwright and May (2013) found that Brook Trout did not switch to aquatic benthos when terrestrial inputs are reduced experimentally as well as natural discharge reduction in summer months in intermittent streams in Virginia. They applied the Strauss selectivity index to stomach contents and prey available in their environment (benthos, drift, accidental terrestrials, and returning aquatic adults), demonstrating no preference towards $\mathrm{Al}^{\prime} \mathrm{s}$. The discrepancy in their results to that of other perineal streams in the area was attributed to an increase in competition with Mottled Sculpin (Cottus bairdii) and reduced mobility between pools.

Conflicting results on prey preference by Brook Trout and other trout relatives makes it difficult to understand their foraging behavior. These differences could simply be attributed to differences between species studied, different geographic study areas as well as different sampling schemes; however, it could also be a product of an improper timescale studied in which switching from opportunistic foraging behavior to a more selective behavior is not captured. Can prey preference be explained by a NEI scenario where the cost of snagging a $\mathrm{TI}$ at the surface is more expensive than a drifting AI? Do the Brook Trout display obvious predator switching behaviors such as when one prey becomes available in a higher abundance that would allow the Brook Trout to meet its daily ration? Is preying upon Tl's a behavior that needs to be learned first? How is predator risk taken into consideration by the Brook Trout? Is there some sort of density-dependent or discharge/flow-dependent threshold whereby Brook Trout may switch modes from subsurface to surface drift feeding? Additionally, some individuals may exhibit different preferences due to differences in fish age, prey exposure, learning capabilities and movement patterns which cause variation within the population. With all these unanswered research questions, there is a need to further understand Brook Trout feeding behavior.

\section{Justification and Potential Implications}

Brook Trout are highly valued for their recreational fishing, palatability, and also as an indicator species (Trout Unlimited, 2006). Since the turn of the century, Brook Trout populations have declined greatly as forested areas were used for timber harvest or converted to agricultural land. As a result, Brook Trout are extirpated from $20 \%$ of subwatersheds. Poor 
land management such as the removal of the riparian corridor, stream modification, and roads and road crossings continue to present hardship for this species. Removal of the riparian vegetation increased stream temperature; roads adjacent to streams increase sedimentation, potentially coating eggs and gills of fish. Overall reduction in watershed connectivity also inhibits the success of this species. Invasive species such as Rainbow and Brown Trout pose a serious threat of outcompeting Brook Trout. Specifically, in West Virginia, only $1 \%$ of the subwatershed populations remain intact (historical ranges have been hard to define given Brook Trout may have disappeared a long time ago) (Trout Unlimited, 2006). Close behind poor land management, Acid Mine Drainage is a major culprit of Brook Trout population declines, highly reducing water quality especially $\mathrm{pH}$. West Virginia has put forth much effort into depositing lime, in the form of limestone gravel, into streams to buffer against low $\mathrm{pH}$.

Recreational fishing proves to be a good management tool of this species, bringing about awareness to the species as well as income in license sales (Hubert \& Quist, 2010). However, Brook Trout fisheries are sometimes over-fished. Even so, these fish prove to be highly sought-after, elusive fish with picky feeding tendencies. Matching the correct fly to whatever the population currently has a search image or taste for can take great expertise. Understanding their foraging behavior might aide in better fishing tactics.

Better understanding their foraging behavior may also be beneficial when predicting how they will be affected by disturbance. Hubert and Quist (2010) categorize disturbances as either a pulse, press or ramp. Pulse occurs in a short timeframe such as a flooding event or chemical spill. In the event of pulse, macroinvertebrate group functionally replacing a previously present group may have different availability to trout (Rader, 1997). For instance, one taxonomic group such as Simuliidae which is more available to trout, can replace the functional niche of Hydropsychidae. Understanding how quickly and successfully a Brook Trout can switch to a new prey would be important in this scenario. A press occurs over a longer timescale; it can begin quickly but the effects are maintained for a period of time such as road construction, removal of riparian vegetation or mining. Changes if the riparian corridor could affect the $\mathrm{TI}$ inputs to streams. The streamside management zone is an established buffer by West Virginia Department of Forestry (WVDF) in which roads and heavy equipment is 
prohibited, but various amounts of basal area removal is not (Studinski \& Hartman, 2015). Again, how a Brook Trout reacts to those TI prey sources is important to understand. Larger natural disturbances, such as superstorm Sandy, have the propensity to redistribute large woody debris in streams; however, higher elevations generally receiving less compared to lower elevations, which increases habitat heterogeneity attractable to Brook Trout (Andrew \& Hartman, 2015).

A ramp occurs of an even longer time and spatial scale such as droughts or even global climate change. Global Climate Change is predicted to increase air temperatures and for every degree $(C)$ increase, $0.6-0.8$ degree $C$ increase in water temperature is expected to occur (Hubert \& Quist, 2010). This has great repercussions for Brook Trout including pushing their habitat range further up the watershed, limiting connectedness between headwater streams, altering metabolism which affects invasive species interactions differently, as well as altering daily ration through-out the year. Furthermore, precipitation and stream discharge duration and frequencies will be altered.

In the process of conservation for this species in central Appalachia, many attributes of the watershed should be considered. The goal consists of watershed connectivity, in which critical spawning and foraging habitat can be accessed by the same Brook Trout population (Petty et al. 2005). Anthropogenic barriers such as culverts, fjords and small dams should be assessed for fish passage. Especially significant to this region, acid remediation programs including limestone input should include lower order streams (Petty et al. 2005). The disconnections in watershed can reduce genetic exchange of a species and reduce the buffering capacity of stochastic events (Hubert \& Quist, 2010). Furthermore, restoring a riparian buffer to headwater streams will create a higher quality environment for Brook Trout. As presented in previous studies (Kraus et al. 2016), head-water streams are highly interconnected with the adjacent terrestrial ecosystem and therefore the protection, and restoration of both these ecosystems is of the upmost importance when managing a Brook Trout fishery. Furthermore, by encompassing head-water streams into the conservation efforts of this species, the surrounding communities will also benefit from quality drinking water and increases in recreational fishing and aquatic sports revenue. 


\section{Literature Cited}

Allan, J. D. 1981. Determinants of diet of Brook Trout (Salvelinus fontinalis) in a mountain stream. Canadian Journal of Fisheries and Aquatic Sciences 38:184-192.

Allan, J. D., \& M. M. Castillo. 2007. Stream Ecology: Structure and function of running waters. Springer, Dordrecht, The Netherlands, pp 214-216.

Allan, J. D., M. S. Wipfli, J. P. Caouette, A. Prussian, \& Joanna Rodgers. 2003. Influence of streamside vegetation on inputs of terrestrial invertebrates to salmonid food webs. Canadian Journal of Fisheries and Aquatic Sciences 60: 309-320.

Allen K.R. 1951. Horokiwi stream: A study of a trout population. New Zealand Marine Department of Fisheries Bulletin 10, Wellington, New Zealand.

Andrew, R., \& K. J. Hartman. 2015. Uneven inputs of woody debris to Appalachian streams from superstorm Sandy. Canadian Journal of Fisheries and Aquatic Sciences 72: 1-6.

Baxter, C. V., K. D. Fausch, \& W. C. Suanders. 2005. Tangled webs: reciprocal flows of invertebrate prey link streams and riparian zones. Freshwater Biology 50:201-220.

Benke A. C., A.D. Huryn, L.A. Smock, \& J.B. Wallace. 1999. Length-mass relationships for freshwater macroinvertebrates in North America with particular reference to the southeastern United States. Journal of the North American Benthological Society 18: 308-343.

Benstead, J. P., M. M. Douglas, \& C. M. Pringle. 2003. Relationships of stream invertebrate communities to deforestation in eastern Madagascar. Ecological Applications 13(5): 1473-1490.

Brittan, J. E., \& T. J. Eikeland. 1988. Invertebrate drift-A review. Hydrobiologia 166: 77-93.

Cada, G. F., J. M. Loar \& D. K. Cox. 1987. Food and feeding preferences of rainbow and Brown Trout in Southern Appalachian Glenn. American Midland Naturalist 117(2): 374-385.

Charnov, E. L. 1976. Optimal foraging: The marginal value theorem. Theoretical Population Biology 9:129-36.

Courtwright, J., \& C. L. May. 2013. Importance of terrestrial subsidies for native Brook Trout in Appalachian intermittent streams. Freshwater Biology 58: 2423-2439.

Dill, L. M. 1983. Adaptive flexibility in the foraging behavior of fishes. Canadian Journal of Fisheries and Aquatic Sciences 40:398-408. 
Dunbrack, R. L., \& L. M. Dil. 1984. Three-dimensional prey reaction field of the juvenile coho salmon (Ohcorhynchus kisutch). Canadian Journal of Fisheries and Aquatic Sciences 41: 1176-1182.

Eros, T., P. Gustafsson., L. A. Greenberg, \& E. Bergman. 2012. Forest-stream linkages: Effects of terrestrial invertebrate input and light on diet and growth of Brown Trout (Salmo trutta) in a boreal forest stream. PLoS ONE 7(5): e36462. doi:10.1371/journal.pone.0036462

Faucsh, K. D. 2014. A historical perspective on drift foraging models for stream salmonids. Environmental Biology Fishes 97:453-464.

Faucsh, K. D., C. E. Torgersen, C. V. Baxter, \& H. W. Li. 2002. Landscapes to riverscapes: bridging the gap between research and conversation of stream fishes. Bioscience 52: 483-48.

Fausch K.D., S. Nakano, \& S. Kitan. 1997. Experimentally induced foraging mode shift by sympatric charrs in a Japanese mountain stream. Behavioral Ecology 8, 414-420.

Forrester, G. E., J. G. Chace, \& W. McCarthy. 1994. Diel and density-related changes in food consumption and prey selection by brook charr in a New Hampshire stream. Environmental Biology of Fishes 39: 301-311.

Frissel, C. A., W. J. Liss, C. E. Warren, \& M. D. Hurley. 1986. A hierarchical framework for stream habitat classification: Viewing streams in a watershed context. Environmental Management 10:199-214.

Giller, P., \& L. Greenberg. 2015. The relationship between individual habitat use and diet in Brown Trout. Freshwater Biology 60: 256-266.

Grant, J. W.A., \& D. L. G. Noakes. 1988. Aggressiveness and foraging mode of young-of the-year brook charr, Salvelinus fontinalis (Pisces, Slamondiae). Behavioral Ecology and Sociobiology 22:435-445.

Gregory, R. S., \& T. G. Northcote. 1993. Surface, planktonic and benthic foraging by juvenile chinook salmon (Oncorhynchus tshawytscha) in turbid laboratory conditions. Canadian Journal of Fisheries and Aquatic Sciences 50:233-240.

Grubaugh, J. W., J. B. Wallace, \& E.S. Houston. 1996. Longitudinal changes of macroinvertebrate communities along an Appalachian stream continuum. Canadian Journal of Fisheries and Aquatic Sciences 53:896-909.

Grubbs, T. C. 2003. The Mind of the Trout. The University of Wisconsin Press, Madison, WI pp. 3-86. 
Gustafasson, P., L. A. Greenberg, \& E. Bergman. 2014. Effects of woody debris and the supply of terrestrial invertebrates on the diet and growth of Brown Trout (Salmo trutta) in a boreal stream. Freshwater Biology 59(12), 2488-2501.

Guy, C., \& M. L. Brown. 2007. Analysis and Interpretation of Freshwater Fisheries Data. American Fisheries Society, Bethesda, MD pp. 765-802.

Kraus, J. M., J. F. Pomeranz, A. S. Todd, D. M. Walters, T. S. Schmidt, \& R. B. Wanty. 2016. Aquatic pollution increase use of terrestrial prey subsidies by stream fish. Journal of Applied Ecology 53: 44-53.

Hansbarger, J. L., Petty, J. T., \& Mazik, P. M. 2010. Brook Trout movement within a highelevation watershed: Consequences for watershed restoration. Proceedings from the Conference on the Ecology and Management of High-Elevation Forests in the Central and Southern Appalachian Mountains GTR-NRS-P-64:74-84.

Hartman, K. J., \& Logan, M. N. 2010. Movement and habitat use by transplanted adult Brook Trout in an Appalachian headwater stream. Northeastern Naturalist 17(3): 357-372.

Hayes J. W., J. D., Stark, \& K. A. Shearer. 2000. Development and test of a whole-lifetime foraging and bioenergetics growth model for drift-feeding Brown Trout. Transactions of American Fisheries Society 129:315-332.

Hubert, W. A., \& M. C. Quist. 2010. Inland Fisheries Management in North America. 3rd Ed. American Fisheries Society, Bethesda, MD, pp. 587-606.

Hughes, H. F. 1992. Selection of positions by drift-feeding salmondis in dominance hierarchies: Model and test for arctic grayling (Thymallus arcticus) in subarctic mountain streams, interior Alaska. Canadian Journal of Fisheries and Aquatic Sciences 49: 1999-2008.

Hughes, N. F. 1998. A model of habitat selection by drift-feeding stream salmonids at different scales. Ecology 79: 281-294.

Hughes, H. F. \& L. M. Dill. 1990. Position choice of drift-feeding salmonids: Model and test for arctic grayling (Thymallus arcticus) in subarctic mountain streams, interior Alaska. Canadian Journal of Fisheries and Aquatic Sciences 47: 2039-2048.

Hynes, H. B. N. 1970. The ecology of running waters. University of Toronto Press. University of Waterloo, Ontario, Canada, pp 365-367, 419, 430-431.

Jenkins, R. E., \& N. M. Burkhead. 1993. Freshwater fishes of Virginia. American Fisheries Society, Bethesda, Maryland. $1079 \mathrm{pp}$ 
Johnsson J. I., \& K. Kjällman-Eriksson. 2008. Cryptic prey colouration increases search time in Brown Trout (Salmo trutta): effects of learning and body size. Behavioral Ecology and Sociobiology 62:1613-1620.

Leung, E. S., J. S. Rosenfeld, \& J. R. Bernhardt. 2009. Habitat effects on invertebrate drift in a small trout stream: implications for prey availability to drift-feeding fish Hydrobiologia 623(1): 113-125.

Mason C. F., \& S. M. MacDonald. 1982. The input of terrestrial invertebrates from tree canopies to a stream. Freshwater Biology 12:305-311.

McLaughlin, R. L., \& J. W. A. Grant. 1994. Morphological and behavioral differences among recently-emerged Brook Trout charr, Salvelinus fontinalis, foraging in slow-vs.-fastrunning water. Environmental Biology of Fishes 39:289-300.

McLaughlin, R. L., M. M. Ferguson, \& D. L. G. Noakes. 1999. Adaptive peaks and alternative foraging tactics in brook charr: evidence of short-term divergent selection for sittingand-waiting and actively searching. Behavioral Ecology and Sociobiology 45: 386-395.

Murdoch, W. W. 1969. Switching in general predators: Experiments on predator specificity and stability of prey populations. Ecol. Soc. of America. Ecological Monographs, 39(4):335354.

Nakano, S., Y. Kawaguchi, Y. Taniguchi, H. Miyasaka, Y. Shibata, H. Urabe, \& N. Kuhara. 1999a. Selective foraging on terrestrial invertebrates by Rainbow Trout in a forested headwater stream in northern Japan. Ecological Research 14(4), 351-360.

Nakano, S., H. Miyasaka, \& N. Kuhara. 1999b. Terrestrial-aquatic linkages: riparian arthropod inputs alter trophic cascades in a stream food web. Ecology 80(7): 2435-2441.

Niles, J. M. 2010. Brook Trout Response to Canopy and Large Woody Debris Manipulations in Appalachian Streams. Doctoral dissertation. West Virginia University, Morgantown.

Petty, J. T., P. J. Lamothe \& P. M. Mazik. 2005. Spatial and seasonal dynamics of Brook Trout populations inhabiting a central Appalachian watershed. Transactions of American Fisheries Society 134 (3): 572-587.

Piccolo, J. J., B. M. Frank, \& J. W Hayes. 2014. Food and space revisited: The role of drift-feeding theory in predicting the distribution, growth, and abundance of stream salmonids. Environmental Biology of Fishes 97:475-488.

Pierce, G. J., \& J. G. Ollason. 1987. Eight reasons why optimal foraging theory is a complete waste of time. Oikos 49: 111-118. 
Polis, G. A. \& S. D. Hurd. 1996. Linking marine and terrestrial food webs: allochthonous input from the ocean and supports high secondary productivity on small islands and coastal land communities. The American Naturalist. 147(3): 396-423.

Polis, F. A., W. B. Anderson, \& R. S. Holt. 1997. Toward an integration of landscape and food web ecology: the dynamic of spatially subsidized food webs. Annual Review of Ecology, Evolution, and Systematics 28:289-316.

Proulx, R. \& P. Magnan. 2004. Contribution of phenotypic plasticity and heredity to the trophic polymorphism of lacustrine brook charr (Salvelinus fontinalis M.). Evolutionary Ecology Research 6:503-522.

Pyke, G. H., H. R. Pulliam, \& E. L. Charnov. 1977. Optimal foraging: a selective review of theory and tests. Quarterly Review of Biology 52:137-154.

Rader, R. B. 1997. A functional classification of the drift: Traits that influence invertebrate availability to salmonids. Canadian Journal of Fisheries and Aquatic Sciences 54:12111234.

Romaniszyn, E. D., J. John, J. Hutchens, \& J. B. Wallace. 2007. Aquatic and terrestrial invertebrate drift in southern Appalachian Mountain streams: implication for trout food resources. Freshwater Biology. 52:1-11.

Rosenfeld, J. S., N. Bouwes, C. E. Wall, \& S M. Naman. 2014. Successes, failures, and opportunities in the practical application of drift-foraging models. Environmental Biology of Fishes 97(5), 551-574.

Saunders, W.C. \& K. D. Fausch. 2007. Improved grazing management increases terrestrial invertebrate inputs that feed trout in Wyoming rangeland streams. Transactions of the American Fisheries Society 136(5): 1216-1230.

Sinervo, B. 1997. Optimal Foraging Theory: Constraints and Cognitive Processes. Behavioral Ecology. University of California, Santa Cruz pp. 105-130.

Studinski, J. M. \& K. J. Hartman. 2015. The effects of riparian logging on terrestrial invertebrate inputs into forested headwater streams. Hydrobiologia 743:189-198.

Sweka, J. A., \& K. J. Hartman. 2001a. Effects of turbidity on prey consumption and growth in Brook Trout and implications for bioenergetics modeling. Canadian Journal of Fisheries and Aquatic Sciences 58: 386-393.

Sweka, J. A., \& K. J. Hartman. 2001b. Fisheries session: Fall and winter Brook Trout prey selection and daily ration. The Proceedings of the Southeastern Association of Fish and Wildlife Agencies 55:8-22. 
Sweka, J. A., \& K. J. Hartman. 2008. Contribution of terrestrial invertebrates to yearly Brook Trout prey consumption and growth. Transactions of the American Fisheries Society 137: 224-235.

Takimoto, G., T. Iwata \& M. Murakami. 2002. Seasonal subsidy stabilizes food web dynamics: Balance in a heterogeneous landscape. Ecological Research. 17:433-439.

Townsend, C.R. \& A.G. Hildrew. 1984. Longitudinal pattern in detritivore communities of acid streams: a consideration of alternative hypotheses. Verhandlungen der Internationalen Vereinigung für Theoretische und Angewandte Limnologie 22: 1953-1958.

Trout Unlimited. 2006. Eastern Brook Trout Joint Venture. Eastern Brook Trout: Status and Threats. Technical Report. Available: http://easternbrooktrout.org/reports/easternbrook-trout-status-and-threats/view (April 2016)

Utz, R. M., \& K. J. Hartman. 2007. Identification of critical prey items to Appalachian Brook Trout (Salvelinus fontinalis) with emphasis on terrestrial organisms. Hydrobiolgia. 575: 259-270.

Vannote, R. L., G. W. Minshall, K. W. Cummins, J. R. Sedell, \& C. E. Cushing. 1980. The river continuum concept. Canadian Journal of Fisheries and Aquatic Sciences 37:130-137.

Ward, J. W. 1986. Altitudinal zonation in a Rocky Mountain stream. Archiv für Hydrobiologie, Supplement 74: 133-199.

Werner, E. E., \& D. J. Hall. 1974. Optimal foraging and the size selection of prey by the bluegill sunfish (Lepomis macrochirus). Ecology 55 (5): 1042-1052.

White, S. L., \& C. Gowan. 2014. Social learning enhances search image acquisition in foraging Brook Trout. Environmental Biology of Fishes 97: 523-528.

Willers, W. B. 1981. Trout Biology: An Angler's Guide. The University of Wisconsin Press, Madison, WI, pp. 128-153.

Wipfli, M.S. 1997. Terrestrial invertebrates as salmonid prey and nitrogen sources in streams: contrasting old-growth and young-growth riparian forests in southeastern Alaska. Canadian Journal of Fisheries and Aquatic Sciences 54:1259-1269.

Wilson, A. D. M., \& R. L. McLaughlin. 2010. Foraging behavior and brain morphology in recently emerged brook charr, Salvelinus fontinalis. Behavioral Ecology and Sociobiology 64:1905-1914. 
Wilson, M. K., W. H. Lowe, \& K. H. Nislow. 2014. What predicts the use by Brook Trout (Salvelinus fontinalis) of terrestrial invertebrate subsidies in headwater streams? Freshwater Biology 59: 187-199.

Zaret, T. M. 1980. Predation and Freshwater Communities. Yale University Press. New Haven, Connecticut and London, England, pp 74-76, 141-142. 


\title{
Chapter 2: Terrestrial versus Aquatic Prey Preference by Trout in Appalachian
}

\section{Headwater Streams}

\begin{abstract}
Brook Trout (Salvelinus fontinalis), are mainly restricted to head-water streams in Appalachia. These environments generally have low autochthonous materials. Therefore, resident aquatic organisms rely heavily on terrestrial inputs, i.e. leaf litter and terrestrial invertebrates (TI's), to subsidize individual energy requirements at critical times of the year. Previous research has mixed results on prey preference, with some suggesting either a feeding preference towards aquatic invertebrates (Al's) or towards $\mathrm{Tl}^{\prime}$ s. Our observational field study of four select streams contained in the Monongahela National Forest, West Virginia was designed to investigate prey preference by Brook Trout. Specifically, we wanted to test our conceptual hypothesis: Brook Trout prefer aquatic invertebrates to terrestrial invertebrates when there are ample amounts of both prey types; when aquatic invertebrate production is low, Brook Trout will switch to a more opportunistic feeding behavior where terrestrial invertebrates are more present in their diets. We employed a hierarchical study design in order to capture the point at which switching in foraging strategies occurred. Of the four selected streams: two-third order and two-first order streams. Within the pair, one stream was selected as having low Al productivity $\left(<500\right.$ individuals $\left./ \mathrm{m}^{2}\right)$, and the other stream selected as having high Al productivity (>1000 individuals/m2). We sampled across spring and summer (2014) to capture changes in Al availability. Since these streams are contained in the national forest, they are relatively unimpaired and allowed for adequate numbers of Brook Trout to be collected. These samples were compared to kicknet samples representing Al's available in the environment. Results show a clear trend, in that, Brook Trout forage on Al's overall, in relatively equal proportions to prey availability in spring and summer. Individual taxa preferences did change as well as size selection across seasons, potentially indicating in the springtime they are foraging more on the benthos and from the drift as well as being more size selective. Furthermore, individual variability exists in which preferences and specialization was shown for either Al's or Tl's in each season. These results suggest Brook Trout are operating under the Optimal Foraging Theory. Brook Trout have the propensity to change their foraging behavior in a short amount of time which will allow them to combat future anthropogenic changes if management efforts are focused on both the surrounding terrestrial landscape (i.e. riparian corridor) as well as the in stream habitat restoration.
\end{abstract}




\section{INTRODUCTION}

Headwater streams are at the interface of watersheds and the surrounding terrestrial, riparian ecosystem. A clear visual boundary between these ecosystems exist, but exchange of biological material can have profound impacts on the biotic communities in each receiving system (Polis \& Hurd, 1996). In headwater riparian areas, huge pulses of emerging aquatic insects are delivered directly to spiders and birds (Baxter et al. 2005; Kraus et al. 2016); however, riparian vegetation greatly subsidizes adjacent streams, in the form of leaf litter by providing energy that is broken down by bacteria and further utilized by the benthic macroinvertebrate community (Baxter et al. 2005; Polis et al. 1997). This is fortunate because headwater stream systems in central Appalachian generally have low primary production or autochthonous materials due to low light penetration caused by high canopy cover (Vannote et al. 1980; Baxter et al. 2005). Terrestrial invertebrates (TI) accidentally falling into headwater streams directly subsidize trout, the top predators of the food web (Baxter et al. 2005; Polis et al. 1997).

The 'Allen Paradox' (Hynes, 1970) best explains this phenomenon, in which trout production is higher than what the benthic macroinvertebrate community can support alone in headwater streams. This paradigm launched a whole series of studies concerning the direct and indirect effects of $\mathrm{TI}$ inputs to the accepting headwater streams community. It has been demonstrated that the presence of terrestrial invertebrates reduces the inevitable trophic cascade caused by trout to a "trophic trickle" during times of low aquatic productivity (Nakano et al. 1999b; Allan \& Castillo, 2007). Takimoto et al. (2002) developed a model that further demonstrates $\mathrm{TI}$ subsidies not only relieve some predation pressure on aquatic invertebrates (AI), but stabilized the food web when autochthonous materials are in short supply.

The implications of $\mathrm{Tl}$ input on trout foraging behavior in head water streams have been greatly studied with mixed results. The forested riparian corridor can greatly influence the diversity and abundance of terrestrial invertebrate inputs. Depending on the tree species, insect composition can differ; for instance, Mason and MacDonald (1982) found sycamore (Platanus occidentalis) contribute more insects to the streams than other trees. Similarly, Allan et al. (2003) found terrestrial invertebrate biomass differed depending of the riparian plant 
species they inhabit including coniferous (lower biomass) as compared to deciduous overstory and understory. When Romanizyn et al. (2007) studied various riparian corridors, they found open canopies and streams adjacent to pastures to have the highest $\mathrm{TI}$ abundances. Relating riparian variables directly to terrestrial invertebrate presence in diets has proven to be difficult, as Wilson et al. (2014) demonstrated in their study on early succession versus late succession riparian forests in New Hampshire. This may be due to the homogenization of $\mathrm{TI}$ abundance and taxonomy, occurring both outside of stream (wind) and instream (water dispersal) (Allan et al. 2003). However, Studinski and Hartman (2015) found that with $90 \%$ basal area removal of trees in the riparian corridor, TI family composition changed and biomass increased while no difference occurred in abundance or richness. They suggested the insect communities shifted from being of forested habitat to decomposing wood and flowering plant habitat, in addition to increases in the overall individual body size. Additional studies have included different vegetation types and agricultural practices (Benstead et al. 2003; Saunders \& Fausch, 2007). It is evident that the amount, composition and importance of TI inputs is difficult to explain in general trends that can encompass all watersheds in different ecotones and be applied directly to trout production.

Seasonal and diel fluctuations reveal clear trends in terrestrial and aquatic invertebrates available in drift and further predict what is present in trout diets. Terrestrial Invertebrate inputs to headwater streams are highest in the spring and summer (Romaniszyn et al. 2007; Nakano et al. 1999a; Mason \& MacDonald, 1982). On a diurnal scale, TI drift was highest at noon and Al's at dusk, which is thought to be a predator avoidance behavior of benthic macroinvertebrates (Rader, 1997). The importance of Terrestrial Invertebrate inputs to trout residing in headwater streams has been supported (see Hynes, 1970; Cada et al. 1987; Nakano et al. 1999a). Many have reported anywhere from $40-77 \%$ of trout diets consist of terrestrial invertebrates. Sweka and Hartman (2008) used bioenergetics to explain that, except for winter months, Brook Trout (Salvelinus fontinalis) rely heavily on large terrestrial invertebrates, such as Coleoptera and Lepidoptera, to fill their daily energy requirement in headwater streams of West Virginia. 
Trout in headwater streams have been categorized as opportunistic generalist foragers operating under the Optimal Foraging Theory (OFT), feeding on prey in accordance to abundance, size, and learned detection for certain prey (Niles, 2010; Allan, 1981). The OFT states foraging behavior is under selective pressure; and a species should weigh the energetic cost of pursuing and capturing prey versus the energetic value of the prey item. (Pierce \& Ollason, 1987; Pyke et al. 1977; Sinervo, 1997). An animal foraging optimally has to make quick decisions on the available prey. For any given species, they may be limited by time, energy, and cognitive abilities (learning and memory) (Sinervo, 1997). Availability of prey across season, and throughout the day also affects a Brook Trout's ability to forage optimally.

Conflicting results on prey preference by Brook Trout and other trout relatives makes it difficult to fully understand their foraging behavior. Some researchers have suggested Rainbow Trout (Oncorhynchus mykiss) and Brown Trout (Salmo trutta) exhibit a feeding preference towards terrestrial prey due to a higher proportion in diets as compared to availability in the environment (Nakano et al. 1999a; Cada, et al. 1987). Eros et al. (2012) experimentally reduced terrestrial input and increased light in boreal coniferous-forested streams. They found Brown Trout, in TI-reduced reaches, to have lower growth rates in the summer than trout in reaches without reductions, suggesting these brown trout may have underutilized the Al's available due to a preference towards TI's. Still other research suggests a preference towards aquatic prey; when exposed to different riparian vegetation management practices; Wilson et al. (2013) showed similar trends; they found a negative relationship with the stream macroinvertebrate abundance and the TI's proportion of terrestrial invertebrates found in diets. In a related study on select Appalachian streams, Niles (2010) artificially increased Al productivity as a product of increased light and organic material from a forestry operation. Brook Trout were found to consume higher amounts of Al's over Tl's. This was despite a coincident increase in largebodied and easily accessible Tl's in the same conditions. In contrast, fish in upstream reference areas continued to consume Tl's, as Al availability remained low (Studinski 2010; Niles, 2010).

This has lead us to develop a conceptual hypothesis: Brook trout in Appalachian headwater streams prefer Al's to $\mathrm{Tl}^{\prime}$ s when there are ample amounts of both prey types; when Al production is low, Brook Trout will switch to a more opportunistic feeding behavior by 
incorporating more TI's into their diets. To address this, a two-fold study design approach was employed to enact changes in the abundance of Als: (1) Selecting streams of different benthic macroinvertebrate productivity hereafter subjectively considered "high" or "low", and (2) utilizing the natural seasonal change in Al biomass that occurs from spring (high) to summer (low) as Al adults emerge to reproduce. If Brook Trout are optimally foraging, then: (1) during periods of high (spring) Al biomass, we expect to see Al preference; As spring progresses into summer, a shift away from Al (if Al biomass is low), TI's will be utilized. (2) Streams with higher Al in spring should show even more specialization towards Al than those with low Al.

\section{METHODS}

\section{Sampling Design and Study Sites}

All streams sampled are located entirely within the Monongahela National Forest, West Virginia in a mesophytic forest type (Figure 2.1). Streams were selected based on adequate Brook Trout densities (based on the 10+ year dataset) to supply the necessary stomach contents specimens. Fish diversity is low in these headwater streams, refer to Appendix 2.2. A hierarchical study design was employed in order to capture the point at which switching in Brook Trout foraging strategies occurred. From a suite of 25 streams that form a long term stream study we selected four headwater streams: two-third order and two-first order streams. Within the pair, one stream was selected as having low Al productivity $\left(<500\right.$ individuals $\left./ \mathrm{m}^{2}\right)$, based on surber samples collected in 2007, and the other stream selected as having high AI productivity ( $>1000$ individuals $/ \mathrm{m}^{2}$ ). To investigate fluctuations throughout the season, sampling days occurred in each stream twice within spring (May $22^{\text {nd }-J u n e ~} 20^{\text {th }} 2014$ ) and summer (July $16^{\text {th }}$-August $31^{\text {st }} 2014$ ) seasons. Only these seasons were selected to capitalize on greatest shifts in Al availability (Romaniszyn et al. 2007). Paired streams were sampled consecutively in a two-day period to minimize the effects of any unusual weather patterns. In order to capture peaks in prey drift during the day, $2-250 \mathrm{~m}$ reaches separated by $250 \mathrm{~m}$ per stream were sampled at noon and dusk for terrestrial and aquatic prey, respectively (Romaniszyn et al. 2007). Description of streams and associated watershed data are found in Table 2.1. 


\section{Field Sampling}

During each sampling time, stomach contents and macroinvertebrate environmental samples were collected and compared to better understand Brook Trout prey preference. Environmental sampling for benthic macroinvertebrates with the propensity to enter drift was collected via kicknet sampling. This encompassed sampling a $0.25 \mathrm{~m}^{2}$ area four times within a 100-m distance. This equated to a full square meter of substrate sampled to acquire density and biomass (drift nets were deployed in this study as well; however, during low flows in summer invertebrate drift could not be determined due to back flow in nets). All samples were preserved in $90 \%$ ethanol until later processing. Additional variables collected included water temperature via YSI meter as well as percent canopy coverage calculated from a densitometer.

Fish were collected directly upstream of kicknet sites. We collected 10-15 Brook Trout (>80 mm total length) via backpack electro-fishing (Zale et al. 2012; Sweka \& Hartman, 2008). Fish were anesthetized in a clove oil/stream water solution. Total length, and weight were acquired followed by extracting stomach contents via gastric lavage which is a non-lethal method for diet collection (Zale et al. 2012). Stomach contents, hereafter denoted as diets, were collected and condensed into a $65 \mu \mathrm{m}$ sieve and rinsed into a sample bottle containing $90 \%$ ethanol.

\section{Processing of Samples}

Kicknet samples were subsampled according to the West Virginia Department of Environmental Protection (WAB Field SOP, 2015). Both kicknet and diet samples, were processed in a laboratory using a binocular dissecting microscope. Individual prey items were identified to the lowest practical taxonomic level, usually family for most insects and vertebrates and order for all other invertebrates. Though temperature increases the rate of metabolism, it was assumed that the digestion rate of hard-bodied prey items has about the same digestion rate at cooler temperatures as compared to higher temperatures (Guy \& Brown, 2007). Nematoda and Nematomorpha present in diets were eliminated from further diet analyses due to their parasite/parasitoid life history involving fish and terrestrial insects, 
respectively (Jim Kotcon, PhD., personal communication, February 5, 2016). All remaining prey items were enumerated, and head width and corresponding body lengths were measured. Simple linear regression was used on body length measurements to extrapolate for those prey items in which only head width could be obtained (due to damage in the gastric lavage method or digestion). With the body lengths, biomass was estimated from published data based on length and dry weight $(\mathrm{mg})$ regression models (Sample et al. 1993; Benke et al. 1999; Sabo et al. 2002; Sage, 1982; Riedel et al. 2012; Huryn \& Wallace, 1987). Except for the subclass Collembola, where average individual weight was obtained from dried bulk samples as followed by the methods of Sample et al. (1993).

\section{Data Analyses}

The kicknet samples were first analyzed to better understand aquatic prey availability. After log10-transforming the data to confirm normality ANOVA was performed in either the statistical program R version 3.2.3 (2015-12-10) or JMP version 12.2.0 (SAS 2015). ANOVA tested the null hypothesis that no differences existed between time of day, between seasons and finally between streams and the associated interactions (Two-way ANOVA, Stream X Season factor, Time of Day nested under Stream. Three-way ANOVA, Season X Stream-Order X Historical Aquatic Productivity factor). Those results could then be compared to aquatic dry mass proportions found in each diet averaged across stream and seasons. Prior to analyzing the diet samples, independent t-tests were performed in Microsoft Excel version 16.0.6701.1013 (2016) on total lengths of fish captured across seasons for each stream and between each stream pair, pooled for season. The Mann Whitney $U$ test was performed in program $R$ to test the null hypothesis that no difference exists between time of day and sampling times of the same season for each stream, However, ANOVA was not performed on the diet data due to not meeting the assumption of normality, which is discussed in the next paragraph. To better understand individual prey present in the diets, diet indices including mean proportion by number $\left(\mathrm{MN}_{\mathrm{i}}\right)$, mean proportion by weight (MWi), frequency of occurrence $\left(\mathrm{O}_{\mathrm{i}}\right)$ and index of relative importance (\%IRI) were utilized. Mean proportion by number is the percentage of prey abundance in diet averaged across all diets. Mean proportion by weight is the percentage of 
prey weight in diet averaged across all diets. Frequency of occurrence is the percentage of diets of individual fish containing that specific prey item. Percent Index of Relative Importance (IRI) is the percentage of IRI compared against all other prey items. Percent IRI is calculated by $\mathrm{MN}_{\mathrm{i}}+$ $\mathrm{MW}_{\mathrm{i}} * \mathrm{O}_{\mathrm{i}}$. Ivlev's index of electivity (Ivlev, 1961) was used to further understand individual aquatic prey preference by using both the diet and kicknet data. This analysis uses a simple equation: $E=\left(r_{i}-p_{i}\right) /\left(r_{i}+p_{i}\right)$ where $E$ is the value of electivity, ranging from 1 to 0 , and 0 to -1 indicating selection or avoidance, respectively, of a particular prey item, $r_{i}$ is the proportion (based on abundance) of prey item in diets against all prey items in that diet, and $\mathrm{p}_{\mathrm{i}}$ is the proportion found in the environment. All samples in each season were pooled for every stream for both diets and kicknet samples separately to obtain Ivlev's values. Prey size often can affect preference; therefore, linear regression was also performed on the averages of prey sizes pooled across all streams for season and prey type (aquatic versus terrestrial) against Brook Trout total length. ANCOVA was further utilized in program $\mathrm{R}$ to test the null hypothesis that no differences between those covariates occurred.

Basic histograms of diets containing a certain proportion of aquatic dry weight for each stream and season revealed strong skewed distributions in the data. Due to losing individual fish variability when transforming the data, Beta regression was performed in program $R$ (package betareg, Cribari-Neto \& Zeileis, 2010) as opposed to basic linear regression or ANOVA. This type of regression allows for more heteroskedastic distributions in proportion data (response variable being between 0 and 1), often with left or right skewness. This ultimately allowed differences among streams across seasons to be better understood.

\section{RESULTS}

\section{Metadata and Kicknet Data}

The metadata of each stream is displayed in Table 2.2. Across all streams, water temperature increases in summer which is expected. Average percent canopy cover were similar across streams, falling within $79.7-87.0 \%$.

Density and biomass of Als across streams and seasons suggested some interesting dynamics of aquatic prey resources. Density of aquatic prey appeared to decrease in the smaller order streams, and increased in the larger order streams from spring to summer (Table 
2.2); Although, only significance occurred in Poca Run and Crooked Fork (t-test, $p=0.025$, $\mathrm{p}=0.027$, respectively). After aquatic dry mass ${ }^{1}$ obtained from the kicknet samples had been log-transformed to confirm normality, a two-way ANOVA for season, stream, stream X season interaction with nested time of day was performed in program R. Significant difference occurred between streams $\left(F_{(3,16)}=4.651, p=0.016\right)$ and between seasons $\left(F_{(1,16)}=4.720, p=\right.$ $0.045)$, but not with a stream by season interaction $\left(F_{(3,16)}=0.141, p=0.93\right)$ nor for sampling periods within the same day $\left(\mathrm{F}_{(4,16)}=1.182, \mathrm{p}=0.36\right)$. Based on these results, we pooled kicknet samples of aquatic dry mass (mg) for time of day and averaged for samples within a season for all streams (Figure 2.2). Across individual streams, dry mass appears to decrease from spring to summer, though individual t-tests did not demonstrate significance due to low sample sizes. However, density of Als increased in summer for the streams of larger watershed area (Crooked Fork and Whites Run) and declined in summer in the smaller watershed pair (Little Branch and Poca Run; Table 2.2). These seasonal changes in biomass and density suggest poorer Al resources in the larger streams in summer because the lower biomass appears coupled with smaller mean sizes (Figure 2.2).

To further test our study design and selection of particular streams, a three-way ANOVA for season, stream-order, historical aquatic productivity, and interactions for all combinations was performed in program JMP. Dry mass was significantly higher in the smaller-order stream as compared to the higher order streams $\left(F_{(1,31)}=11.2819, p=0.00261\right)$. Dry mass in Spring was close to being significantly higher than Summer $\left(F_{(1,31)}=3.9034, p=0.0598\right)$; however, no significance occurred between streams set at high and low aquatic productivity based on historical data $(F(1,31)=0.1062, p=0.7474)$. No significant differences existed for any interactions; Season $X$ Productivity $X \operatorname{Order}\left(\mathrm{F}_{(1,31)}=0.2772, \mathrm{p}=0.6034\right)$, Productivity $X$ Order $\left(F_{(1,31)}=0.2574, p=0.6165\right)$, Season X Productivity $\left(F_{(1,31)}=0.0015, p=0.9693\right)$.

\footnotetext{
${ }^{1}$ Urodela and one larger Decapoda were removed prior to analyzing to prevent bias, Aquatic dry mass (mg) plotted against stream and season with these prey items included can be found in the Appendix 2.1.
} 


\section{Diet Samples and Ivlev's Electivity Index}

Adequate numbers of Brook Trout were collected to perform gastric lavage per sampling time (average $n=9.3$, range $6-12$ ), and any fish containing empty stomachs were eliminated from further analyses. A total of 283 Brook Trout stomachs were analyzed with 141 in spring and 142 in summer. No significant differences in average fish total lengths between seasons for each stream occurred (Table 2.3). However, each stream-order pair had significant differences in fish total length averaged across seasons; Whites Run's average (167.2 mm) was significantly higher than Crooked Fork's average (129.5 mm, p<0.001), as well as Poca Run's average $(163.3 \mathrm{~mm})$ was significantly higher than Little Branch's average $(119.1 \mathrm{~mm}, \mathrm{p}<0.001)$.

No differences in mean proportion of aquatic prey dry weight existed in diet samples between time of day (noon versus evening) in all streams and seasons except in the first summer samples in Poca Run (Mann Whitney $U$ Test, $p=0.021$ ). No differences in mean proportion of aquatic prey dry weight existed between diet samples within the same season, pooled across time of day, in all streams and seasons except spring samples in Poca Run, and summer samples in Whites (Mann Whitney $U$ Test, $p$-value $=0.033, p=0.012$, respectively). The mean proportion aquatic prey dry weight pooled for each stream and season is represented in Figure 3, which shows the trend as spring progresses into summer, proportion of aquatic biomass decreases. Crooked appears to be the exception to this, with approximately equal proportions across seasons.

Brook Trout consumed a wide variety of taxa; the 13 most common prey items with the associated diet indices $\left(\mathrm{MN}_{\mathrm{i}}, \mathrm{NW}_{\mathrm{i}}, \mathrm{O}_{\mathrm{i}}, \% \mathrm{IRI}\right)$ for each stream and season are presented in Tables 4-7. Crooked Fork fish appear to not shift their taxa preferences, and utilized predominantly terrestrial prey; although the \%IRI for Coleoptera and Diptera decreased from spring to summer. Whites Run as well as Poca Run, and to a lesser extent Little Branch, have drastic \%IRI decreases in Ephemeroptera, Plecoptera, and Trichoptera (EPT) aquatic taxa and increases in adult Diptera, and various other terrestrial invertebrates from spring to summer.

Ivlev's Electivity Index based on aquatic abundance found in diets and kicknet samples for each stream and season suggested selection against taxa in the kicknets with only a few prey preferences (Figures 2.4-2.7). Prey taxa were grouped based on abundance in diets and 
drift propensity. Preference or selection of certain prey is indicated by positive values. In all streams, and seasons it appears there is variation in selectivity values with most prey items having negative selection. However, this is across all prey items in the kicknet data and may not fully represent environmental availability, so focus should be paid to the relative values across seasons.

Across all streams, most aquatic prey items have a decrease in selection in summer. Decapoda seems to be preferred more in spring versus summer in all streams except Little Branch, and Urodela shows variable preferences across seasons and streams. For the larger order streams, benthic obligates (i.e. case-bearing Trichoptera and Ephemeridae) decrease in preference across seasons. Diptera, Plecoptera, and most Ephemeroptera categories, aside from Heptageniidae, decrease in summer in the larger order streams as well. In the smaller orders streams, case-bearing Trichoptera selection decreased in summer; Ephemeridae did not appear to show the same trends as in the larger order streams, due to overall limited availability in the smaller order streams. The smaller order streams also have decreases in selection of most aquatic prey categories; although, this trend is more apparent in Poca Run. In Figures 2.8 and 2.9, it is apparent that size of prey is important in prey selection. A general trend of larger fish selecting larger prey is evident (slope $=0.016, R^{2}=0.057, p<0.001$ ); trout may not be more size selective in spring versus summer (spring slope $=0.017, R^{2}=0.069, p<0.001$; summer slope $=0.015, R^{2}=0.037, p=0.013$ ), which was not statistically significant (ANCOVA $p$ value for interaction $=0.64$, in program JMP). Trout are, however, more selective of aquatic prey (slope $=0.028, R^{2}=0.076, p<0.001$ ) versus terrestrial prey (slope $=0.0095, R^{2}=0.012, p=0.047$ ), which was statistically significant (ANCOVA p-value for interaction $=0.017$ ).

\section{Population and Individual Prey Selection}

To better understand prey diversity at the individual level the proportions of aquatic macroinvertebrates (based on biomass) was plotted against the frequency of diets as seen in Figures 2.10-2.13. Overall, there appears to be a split of a majority of the diets having either high proportions of aquatic or terrestrial prey. This dichotomy in feeding behavior is more apparent in the spring time. This relationship seems to degrade in summer, in which there are 
more diets containing terrestrial prey items versus having a split in diets of aquatic or terrestrial. These trends appear to be clearer for the historically higher aquatic productivity streams (i.e. Whites and Poca). Crooked seems to be the exception to this pattern, in that most diets contain low aquatic proportions. This can be attributed to low aquatic biomass in both the spring and summer seasons. A Chi-square test was performed in which equal counts of diets across all proportions of aquatic biomass was predicted. All streams in all seasons were significant ( $p$-value $<0.05$ ) indicating unequal distribution of diet counts across all proportions, except for Little Branch in the spring, which appears to have some diets with a variety of aquatic proportions, but still a majority utilizes aquatic only. Beta regression further corroborated this. Though no significance was found in Little Branch or Crooked Fork ( $p=0.11$, $\mathrm{p}=0.28$, respectively) both Poca and Whites Runs' aquatic prey proportions were significantly different from all other streams ( $p<0.001$ for each). As spring progressed into summer, Crooked Fork's aquatic proportions increased while Little Branch, Poca Run and Whites Run decreased, but significance only occurred in Poca and Whites run (interaction with sampling date, $p=0.0039, p<0.001, p=0.22, p=0.44$, for Poca Run, Whites Run, Little Branch and Crooked Fork, respectively).

\section{Discussion}

Prey Availability and Selection in Our Study Streams

Brook Trout and other stream-dwelling trout rely on terrestrial invertebrate inputs to headwater streams especially during summer months when aquatic invertebrate prey sources are depleted (Sweka \& Hartman, 2008). This was corroborated by our data collected from the diets of Brook Trout and corresponding Al data from our four streams. All streams in this study had approximately equally high percent canopy cover suggesting an equal propensity of terrestrial prey accidentally falling into the streams. Aquatic dry mass collected from the kicknet sampling demonstrated a decrease from spring to summer in all streams potentially due to emergence and burrowing behavior of macroinvertebrates during low flows (Rader, 1997). The larger order streams both had decreases in biomass, but increases in densities from spring to summer. The reverse was apparent with the smaller order streams, possibly indicating that 
available prey stayed relatively the same size, but were depleted or emigrated progressing into summer. Little Branch, the supposed low-aquatic productivity stream, had unexpectedly high amounts of biomass across both seasons, very comparable to its high-aquatic productivity pair, Poca Run. The historical aquatic biomass we used to select the streams was based on one sample and thus may not have been properly representing productivity for this stream.

Brook Trout may be feeding on aquatic prey directly proportional to availability in the environment (Figure 2.2 and 2.3). Little Branch Brook Trout may be the exception to this in which they may be utilizing aquatic macroinvertebrates at a slightly higher proportion than what is found in the environment, especially during summer. This may be attributed to overall terrestrial availability being low across seasons compared to the three other streams. More conifers (e.g. Eastern Hemlock Tsuga Canadensis) reside in the riparian zone in this stream which produce less terrestrial insects (Allan et al. 2003). Investigating the coniferous and deciduous species composition in the riparian corridor for each stream may further elucidate $\mathrm{TI}$ contribution.

Results of the beta regression showed significance with the two higher-productivity streams, Whites and Poca Run, at explaining proportion of aquatic biomass in relation to sampling date. This indicates that as spring progresses into summer, Al's are less present in diets, in which Brook Trout switch to terrestrial prey. The diet indices, and Ivlev's Electivity Index also indicate that as spring progresses into summer, use of aquatic prey decreases. In particular, there may be selection of benthic-obligate prey in spring suggesting, Brook Trout are possibly feeding in the benthic/drift zone and switch to drift/surface feeding in the summer.

The basic histograms (Figures 2.10-2.13) of proportion of aquatic biomass in individual diets are important. It appears that Brook Trout are partitioning the resources i.e. displaying two feeding strategies, either feeding mostly on aquatic or mostly on terrestrials even when aquatic prey is abundant. When the aquatic and potentially overall prey abundance is low, Brook Trout switch to a more opportunistic feeding behavior in which they not only incorporate more terrestrials into their diets, but a wider variety of sizes as well (Figures 2.8-2.13). Crooked Fork had low aquatic invertebrate biomass in spring and summer. As a result, individual Brook Trout concentrated on TIs more than individuals in the other streams with higher Al biomass, 
even in the spring. Similar results were produced by Kraus et al. (2016) who demonstrated that Brown Trout and Brook Trout switch to foraging on terrestrial insects from aquatic macroinvertebrates, with increases in aqueous metal contamination. These researchers even go as far as to suggest that these trout are developing a compensatory mechanism by depending on terrestrial insects when aquatic macroinvertebrates are reduced due to pollution.

\section{Other Factors Influencing Foraging Behavior}

Many mechanisms may be at work in headwater streams contributing to differences in foraging behavior in addition to differences in seasonal prey availability. These include individual and social learning, changes in stream temperature, variability in prey density and composition between microhabitats within the same stream, as well as density dependent factors. Learning can have great adaptive benefits in trout; a prey item must be encountered in enough sequence in order for an individual to develop a search image for it (White \& Gowan, 2014). Brook Trout may also be developing search images for prey at a specific location of the water column in which some are specializing on the benthos (cased Trichoptera versus freeliving entering drift), drift, vegetation and rocks near banks (where naiads and pupae are emerging), and at surface. Often biases are developed for a particular prey item at the individual fish level (Dill, 1983). Social learning aids to combat this and allows an individual trout to quickly access prey availability when entering a new stream, as demonstrated by White and Gowan (2014).

Movement of individuals may also influence foraging behavior. Movement out of headwater streams, especially by larger adults, is primarily due to limited foraging resources. Larger adult Brook Trout tend to emigrate to larger-order streams in spring and summer in which macroinvertebrates provide the necessary biomass to meet their daily ration and move back into natal streams during fall spawning times (Petty et al. 2005). Of the remaining smaller individuals, most appear to be sedentary (home ranges between $301 \mathrm{~m}$ and $637 \mathrm{~m}$ ) in the springtime when headwater streams are most productive, with a small portion of the population moving greater distances (>900m) (Hartman \& Logan, 2010; Hansbarger et al. 2010). Trout can quickly understand availability by viewing others' foraging behavior and success, 
thereby amplifying number of individuals employing a specialist strategy during the springtime (i.e. selecting predominately terrestrial or aquatic prey). Furthermore, trout have the opportunity to foraging in riffles and pools, which also aids in developing specialist strategies due to variation in prey availability. Grubaugh et al. (1996) found cobble riffle habitats to produce the highest macroinvertebrate diversity in head-water to mid-order streams in Southern Appalachian Mountains, NC. Different velocities associated with changing microhabitats (e.g. pools to riffles) concentrate resources and alter energy intake and growth of a drift forager (Giller \& Greenberg, 2015; Gustafsson et al. 2014). Giller \& Greenberg (2015) identified two types of feeding tactics, 'movers' and 'stayers', in a Brown Trout stream population in Sweden. Stayers of a pool habitat generally had more terrestrials and overall diversity in their diets as comparted to stayers of riffle habitat. Stayers of riffle habitats ingested more aquatic invertebrates and had an overall higher abundance of prey, but that could be attributed to the smaller size of prey and higher velocities. Movers had a more intermediate diet due to moving between riffle and pool habitats and furthermore, may never enter a dominance hierarchy.

Movement is also affected by water temperature due to increases in metabolism; In Arctic Grayling (Thymallus arcticus), a close relative of trout, Hughes (1998) proposed the largest individual will be present in colder temperatures, higher up in a stream to reduce energetic cost when food is scarce. If food is plentiful, larger individuals will occupy warmer parts of the stream or watershed to capitalize on prey by attaining a higher metabolism. This relates to our results, in that we see specialized feeding strategies, i.e. foraging predominately on aquatics or terrestrial prey, in the spring time when trout are more capable of moving into different macrohabitats. Those fish that develop a stayer strategy in pools may be utilizing more terrestrials falling onto the surface of the water versus stayers of riffles primarily foraging on aquatic macroinvertebrates concentrated in the drift. With that said, there are potentially less dominant individuals who will be foraging on anything available, whether it be terrestrial or aquatic, in order to feed optimally.

When spring progresses into summer, variable movement is expected to occur (Hartman \& Logan, 2010). Flows decrease causing fish to reside mainly in pools, where aquatic 
prey are quickly depleted. With the compound effect of reduced aquatic prey, reduced habitat, increase in competition and increase in metabolic demands due to seasonal temperature rise, trout have no other choice but to switch to generalist feeding in order to meet their daily energy ration. This ultimately means a widening in diet breadth not only in taxa diversity, but sizes of prey and location of prey, as we saw in our fish. Size of prey item is probably the best measure of its worth to a predator; larger prey usually indicates more energy pay off (Sinervo, 1997). However, Rader (1997) proposed that an increase in handling time may make ingesting a prey not worth the energy gained versus energy expended. This may be why we see more sporadic intakes of varying prey sizes by individual fish during summer (Figure 2.13), when Brook Trout are likely more desperate for food.

Density dependency factors can have great implications for Brook Trout residing in headwater streams. Juvenile trout in streams develop individual territories to defend food resources (Willers, 1981). As fish grow, their need for energy increases; territories eventually become too large, overlap and diminish. These larger fish move into locations within the stream better suited for drift feeding to establish a more complicated set of territories known as the dominance hierarchy. Fausch (2014) described the drift foraging theory which has launched drift foraging models to predict the best position possible for an individual in a dominance hierarchy based on its ability to defend that position and have access its own 'foraging window'. In the case of our streams sampled, as fish density increases, potentially from movement as in the springtime, dominance hierarchies are established. This limits an individual's access to prey in drift, which is potentially why we see specialization on prey items not specifically contained in the drift during that season. In our larger order streams in particular, Whites Run has over twice the historical fish density as Crooked (Table 2) potentially contributing to increased competition in Whites Run and specialization on prey.

\section{Conclusions}

Overall, our results support our conceptual hypothesis. Brook Trout ingest Al's potentially in equal proportions to availability, but may prefer aquatic invertebrates in the most favorable environmental circumstances (though this can only be implied from our results due to 
lacking $\mathrm{Tl}$ availability). This includes spring time when Al biomass is the highest especially in more productive streams (i.e. Whites and Poca Runs). Although we did not test the Optimal Foraging Theory directly through model development, direct field observations of behavior or collection of total prey availability (i.e. lacking TI input estimates), broadly speaking, it appears Brook Trout are operating under this theory. The "average" fish behavior maximizes fitness (Pyke \& Charnov, 1977) by utilizing mainly Al's in spring due to higher availability, ideal size for consumption and accessibility (i.e. present directly in water column and on substrate). Fish then incorporate a wider variety of sizes as well as more TI's in the summer, due to overall lower Al availability. This may cost more energetically to the fish to capture smaller prey items or larger prey items with increased handling times, in addition to traveling farther distance for prey with sporadic availability (i.e. TI's at water surface/subsurface), but must be done to meet their daily energy ration. At the individual level, different adaptive peaks in foraging behavior as a product of resource partition occurred (Figures 2.10-2.13). A majority of individuals capitalized on Al's and TI's in spring and summer, respectively; a lower number of individuals focused their efforts on less available prey in each season. This allowed each individual to increase survival and maximize fitness.

\section{Implications and Suggestions to Management}

Brook Trout have been extirpated from $20 \%$ of subwatersheds of its natural range, due to natural resource extraction since the turn of the century (Trout Unlimited, 2006). These fish may continue to face population declines caused by future compounding anthropogenic effects including poor land management practices of the riparian corridor, stream and road modification, acid mine drainage (AMD), invasive species competition and an overall increase in stream temperature due to global climate change. Though removal of the riparian corridor may shift the terrestrial community and create temporary pulses of biomass entering the stream, Brook Trout will only briefly benefit by shifting foraging efforts towards terrestrials (Studinski \& Hartman, 2015); this may not mediate the longer-lasting effects such as sedimentation, coating gills and eggs, and stream temperature increases causing increases in metabolic demands. Obstruction to the riparian corridor in addition to anthropogenic chemical (e.g. AMD) and 
physical barriers (road crossings) further reduces movement to critical habitat in an already patchy landscape as (Petty et al. 2005). Global climate change is predicted to increase air temperatures and for every degree (C) increase, 0.6-0.8-degree C increase in water temperature is expected to occur (Huber \& Quist, 2010). This also limits mobility and further reduces available habitat. These issues previously mentioned, in addition to increased competition with warmer guilds such as Smallmouth Bass (Micropterus dolomieu) as temperatures rise, or invasive Brown and Rainbow Trouts can ultimately increase competitive pressures. As presented in our data, Brook Trout have the propensity to partition their prey resources by specializing on particular prey items (terrestrial vs aquatic) in potentially high fish densities when ample amounts of both prey items are available (i.e. Whites Run in the springtime), and are also able to switch their foraging tactics towards most available prey in a short amount of time (i.e. transitioning from spring to summer). However, with overall limited mobility and increased thermal stress, Brook Trout will face population declines due to lower body condition by not meeting their daily ration brought on by competition during those summer months.

Efforts by fisheries and resource professionals should be focused on improving the riparian corridor through best management practices for adequate and consistent Tl's inputs. Acid remediation programs involving limestone sand input to streams should continue and include lower order streams to stabilize Al production. Creating more diverse stream habitat, via LWD inputs and instream modification (i.e. k-dams and j hooks) will not only create thermal refugia but create diversity in aquatic macroinvertebrate biomass and composition between microhabitats. Brook Trout are highly valued for their recreational fishing, palatability, and also as an indicator species (Trout Unlimited), so their conservation should be of top priority. 


\section{Literature Cited}

Allan, J. D. 1981. Determinants of diet of Brook Trout (Salvelinus fontinalis) in a mountain stream. Canadian Journal of Fisheries and Aquatic Sciences 38:184-192.

Allan, J. D., \& M. M. Castillo. 2007. Stream Ecology: Structure and function of running waters. Springer, Dordrecht, The Netherlands, pp 214-216.

Allan, J. D., M. S. Wipfli, J. P. Caouette, A. Prussian, \& Joanna Rodgers. 2003. Influence of streamside vegetation on inputs of terrestrial invertebrates to salmonid food webs. Canadian Journal of Fisheries and Aquatic Sciences 60: 309-320.

Allen K.R. 1951. Horokiwi stream: A study of a trout population. New Zealand Marine Department of Fisheries Bulletin 10, Wellington, New Zealand.

Baxter, C. V., K. D. Fausch, \& W. C. Suanders. 2005. Tangled webs: reciprocal flows of invertebrate prey link streams and riparian zones. Freshwater Biology 50:201-220.

Benstead, J. P., M. M. Douglas, \& C. M. Pringle. 2003. Relationships of stream invertebrate communities to deforestation in eastern Madagascar. Ecological Applications 13(5): 1473-1490.

Bridcut, E. E. \& Giller, P.S. 1995. Diet variability and foraging strategies in brown trout (Salmo trutta): an analysis from subpopulations to individuals. Canadian Journal of Fisheries and Aquatic Sciences. 52: 2543-2552.

Cada, G. F., J. M. Loar \& D. K. Cox. 1987. Food and feeding preferences of rainbow and brown trout in Southern Appalachian Glenn. American Midland Naturalist 117(2): 374-385.

Cribari-Neto, F., \& A. Zeileis, 2010. Beta Regression in R. Journal of Statistical Software 34(2), 1-24. Available from http://www.jstatsoft.org/v34/i02/.

Dill, L. M., 1983. Adaptive flexibility in the foraging behavior of fishes. Canadian Journal of Fisheries and Aquatic Sciences 40:398-408.

Eros, T., P. Gustafsson., L. A. Greenberg, \& E. Bergman. 2012. Forest-stream linkages: Effects of terrestrial invertebrate input and light on diet and growth of brown trout (Salmo trutta) in a boreal forest stream. PLoS ONE 7(5): e36462. doi:10.1371/journal.pone.0036462

Faucsh, K. D., 2014. A historical perspective on drift foraging models for stream salmonids. Environmental Biology of Fishes 97:453-464. 
Giller, P., \& L. Greenberg. 2015. The relationship between individual habitat use and diet in brown trout. Freshwater Biology 60: 256-266.

Grubaugh, J.W., J.B. Wallace, \& E.S. Houston. 1996. Longitudinal changes of macroinvertebrate communities along an Appalachian stream continuum. Canadian Journal of Fisheries and Aquatic Sciences 53: 896-909.

Gustafasson, P., L. A. Greenberg \& E. Bergman. 2014. Effects of woody debris and the supply of terrestrial invertebrates on the diet and growth of brown trout (Salmo trutta) in a boreal stream. Freshwater Biology 59(12), 2488-2501.

Guy, C. \& M. L. Brown. 2007. Analysis and Interpretation of Freshwater Fisheries Data. American Fisheries Society, Bethesda, MD pp. 765-802.

Hansbarger, J. L., Petty, J. T., \& Mazik, P. M. 2010. Brook trout movement within a highelevation watershed: Consequences for watershed restoration. Proceedings from the Conference on the Ecology and Management of High-Elevation Forests in the Central and Southern Appalachian Mountains GTR-NRS-P-64:74-84.

Hartman, K. J., \& Logan, M. N. 2010. Movement and habitat use by transplanted adult brook trout in an Appalachian headwater stream. Northeastern Naturalist 17(3): 357-372

Hubert, W. A., \& M. C. Quist. 2010 Inland Fisheries Management in North America. 3rd Ed. American Fisheries Society, Bethesda, MD, pp. 587-606.

Hughes, H. F. \& L. M. Dill. 1992. Position choice of drift-feeding salmonids: Model and test for arctic grayling (Thymallus arcticus) in subarctic mountain streams, interior Alaska. Canadian Journal of Fisheries and Aquatic Sciences 47: 2039-2048.

Huryn, A. D. \& Wallace, J. B. 1987. Production and litter processing by crayfish in an Appalachian mountain stream. Freshwater Biology 18: 277-286.

Hynes, H. B. N. 1970. The ecology of running waters. University of Toronto Press. University of Waterloo, Ontario, Canada, pp 365-367, 419, 430-431.

Ivlev, V. S. 1961. Experimental ecology of the feeding of fishes. Yale University Press, New Haven, Connecticut, USA.

$\mathrm{JMP}^{\circledR}$, Version 12.2.0 (32-bit). SAS Institute Inc., Cary, NC, 1989-2015.

Kraus, J. M., J. F. Pomeranz, A. S. Todd, D. M. Walters, T. S. Schmidt, \& R. B. Wanty. 2016. Aquatic pollution increase use of terrestrial prey subsidies by stream fish. Journal of Applied Ecology 53: 44-53. 
Mason C. F., \& S. M. MacDonald. 1982. The input of terrestrial invertebrates from tree canopies to a stream. Freshwater Biology 12:305-311.

Nakano, S., Kawaguchi, Y., Taniguchi, Y., Miyasaka, H., Shibata, Y., Urabe, H., \& Kuhara, N. 1999a. Selective foraging on terrestrial invertebrates by rainbow trout in a forested headwater stream in northern Japan. Ecological Research 14(4), 351-360.

Niles, J. M. 2010. Brook Trout Response to Canopy and Large Woody Debris Manipulations in Appalachian Streams. Doctoral dissertation, West Virginia University, Morgantown.

Nakano, S., H. Miyasaka, \& N. Kuhara. 1999b. Terrestrial-aquatic linkages: riparian arthropod inputs alter trophic cascades in a stream food web. Ecology 80(7): 2435-2441.

Petty, J. T., P. J. Lamothe \& P. M. Mazik. 2005. Spatial and seasonal dynamics of Brook Trout populations inhabiting a central Appalachian watershed. Transactions of American Fisheries Society 134 (3): 572-587.

Pierce, G. J., \& Ollason, J. G. 1987. Eight reasons why optimal foraging theory is a complete waste of time. Oikos 49: 111-118.

Polis, F. A., W. B. Anderson, \& R. S. Holt. 1997. Toward an integration of landscape and food web ecology: the dynamic of spatially subsidized food webs. Annual Review of Ecology, Evolution and Systematics. 28:289-316.

Pyke, G. H., H. R. Pulliam, \& E. L. Charnov. 1977. Optimal foraging: a selective review of theory and tests. Quarterly Review of Biology 52:137-154.

R Core Team, 2015. R: A language and environment for statistical computing. R Foundation for Statistical Computing, Vienna, Austria. Available from http://www.R-project.org/.

Rader, R. B. 1997. A functional classification of the drift: Traits that influence invertebrate availability to salmonids. Canadian Journal of Fisheries and Aquatic Science 54:12111234.

Riedel, B. L., K. R. Russell, \& W. M. Ford. 2012. Physical condition, sex, and age-class of Eastern Red-Backed Salamanders (Plethodon cinereus) in forested and open habitats of West Virginia, USA. International Journal of Zoology vol. 2012, Article ID 623730, 8 pages, 2012. doi:10.1155/2012/623730

Romaniszyn, E. D., J. John, J. Hutchens, \& J. B. Wallace. 2007. Aquatic and terrestrial invertebrate drift in southern Appalachian Mountain streams: implication for trout food resources. Freshwater Biology. 52:1-11. 
Sabo, J. L., J. L. Bastow, \& M. E. Power. 2002. Length-mass relationships for adult aquatic and terrestrial invertebrates in a California watershed. The Journal of the North American Benthological Society 21(2):336-343.

Sage, R. D. 1982. Wet and Dry-weight Estimates of Insects and Spiders Based on Length. The American Midland Naturalist 108(2): 407-411.

Sample B.E., Cooper R.J., Greer R.D. \& Whitmore R.C. 1993. Estimation of insect biomass by length and width. American Midland Naturalist 129: 234-240.

Saunder, W.C. \& Kurt D. Fausch. 2007. Improved grazing management increases terrestrial invertebrate inputs that feed trout in Wyoming rangeland streams. Transactions of the American Fisheries Society 136(5): 1216-1230.

Sinervo, B. 1997. Optimal Foraging Theory: Constraints and Cognitive Processes. Behavioral Ecology. University of California, Santa Cruz pp. 105-130.

Studinski, J. M. \& K. J. Hartman. 2015. The effects of riparian logging on terrestrial invertebrate inputs into forested headwater streams. Hydrobiologia 743:189-198.

Sweka, J. A., \& K. J. Hartman. 2008. Contribution of terrestrial invertebrates to yearly Brook Trout prey consumption and growth. Transactions of the American Fisheries Society 137: 224-235.

Takimoto, G., T. Iwata \& M. Murakami. 2002. Seasonal subsidy stabilizes food web dynamics: Balance in a heterogeneous landscape. Ecological Research. 17:433-439.

Tokeshi, M. 1991. Graphical analysis of predator feeding strategy and prey importance. In Freshwater forum. Vol. 1 Freshwater Biological Association. Ambleside. U. K. pp. 179183.

Trout Unlimited. 2006. Eastern Brook Trout Joint Venture. Eastern Brook Trout: Status and Threats. Technical Report. Available http://easternbrooktrout.org/reports/easternbrook-trout-status-and-threats/view (April 2016).

Vannote, R. L., G. W. Minshall, K. W. Cummins, J. R. Sedell, \& C. E. Cushing. 1980. The river continuum concept. Canadian Journal of Fisheries and Aquatic Sciences 37:130-137.

Watershed Assessment Branch 2015 Field Sampling Standard Operating Procedures. Chapter Five: Benthic Macroinvertebrate Collection Protocols. West Virginia Department of Environmental Protection Division of Water and Waste Management Watershed Assessment Branch. Available From http://www.dep.wv.gov/WWE/watershed/Pages/WBSOPs.aspx 
White, S. L., \& C. Gowan. 2014. Social learning enhances search image acquisition in foraging Brook Trout. Environmental Biology of Fishes 97: 523-528.

Willers, W. B. 1981. Trout Biology: An Angler's Guide. The University of Wisconsin Press, Madison, WI, pp. 128-153.

Wilson, A. D. M., \& R. L. McLaughlin. 2010. Foraging behavior and brain morphology in recently emerged brook charr, Salvelinus fontinalis. Behavioral Ecology and Sociobiology 64:1905-1914.

Zale, A. V., D. L. Parrish \& T. M. Sutton. 2012. Fisheries Techniques, Third Edition. American Fisheries Society, Bethesda, Maryland, pp. 340, 479-480, 733-779. 
Figures and Tables

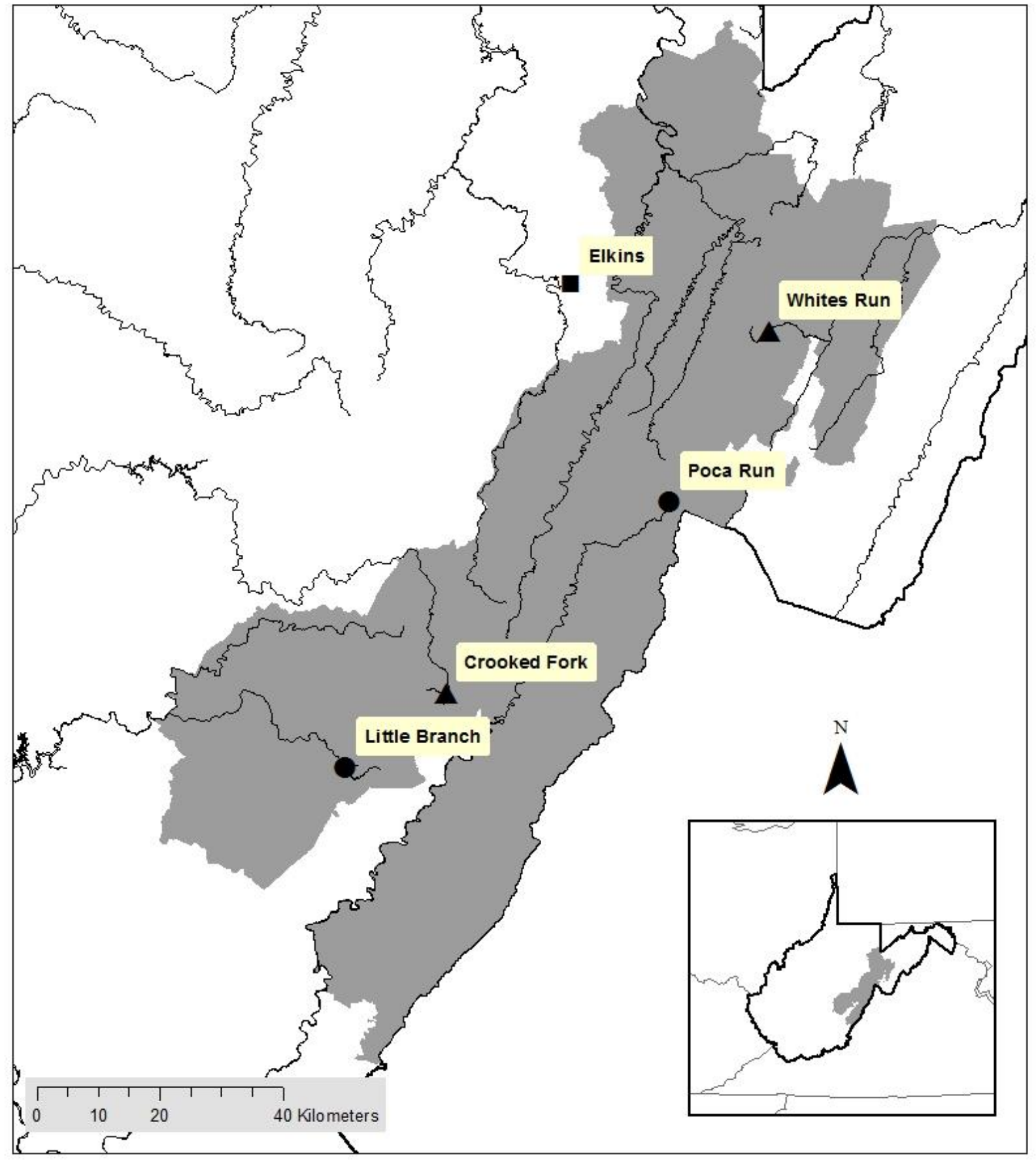

Figure 2.1. Map showing the location of headwater streams sampled for this study. The lowerorder stream pair is depicted by the black circles and the higher-order stream pair is depicted by the black triangles. All headwater streams were contained in the Monongahela National Forest, West Virginia, depicted in gray. 

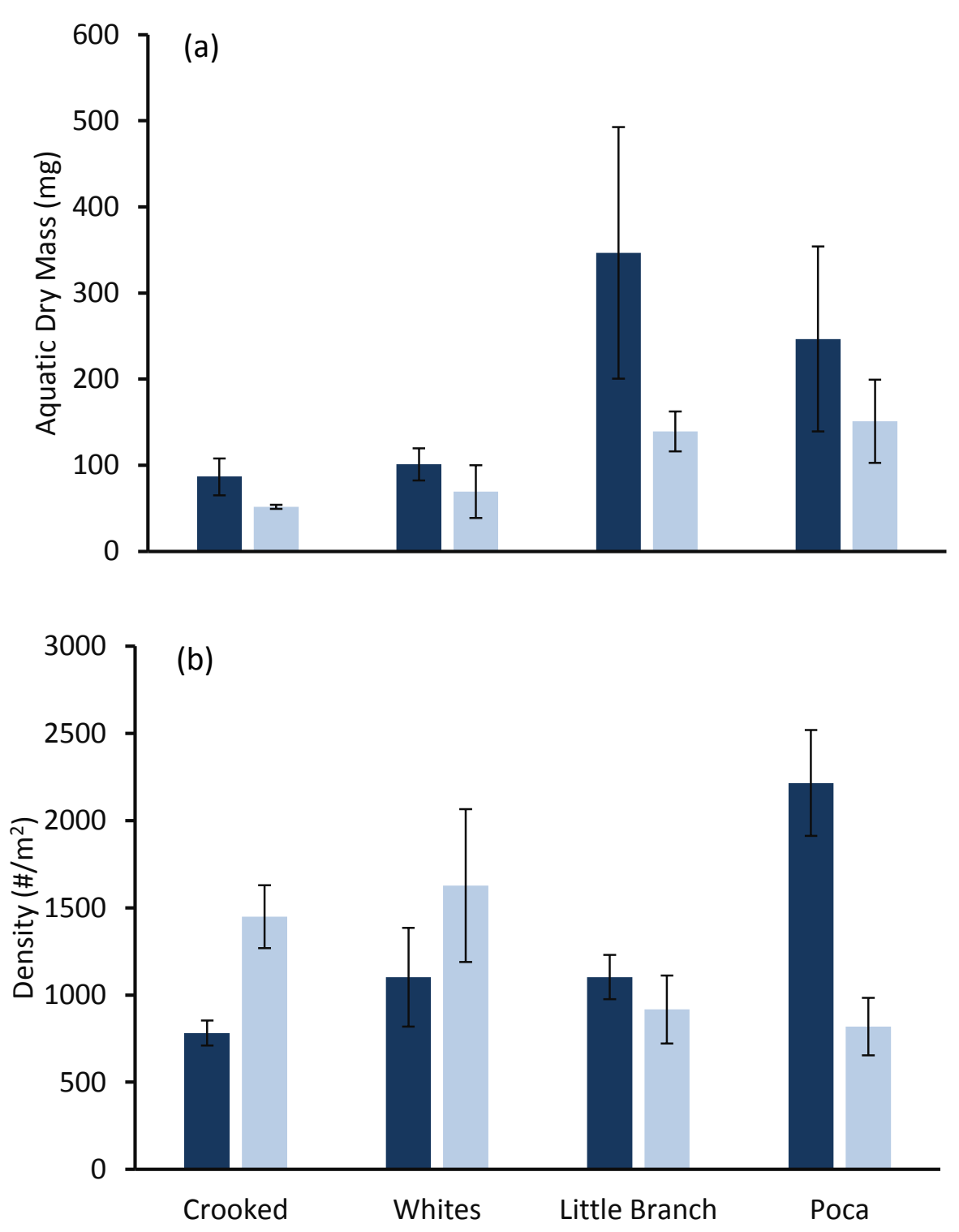

Figure 2.2. Dry mass (mg) of aquatic prey (a) collected via kicknet sampling for each stream. Large prey items, including Urodela and one large Decapoda, were removed to prevent bias. Aquatic prey density (\#/m²) (b) collected via kicknet sampling (no prey items removed from analysis). Spring is depicted in dark blue and summer in light blue. Error bars represent standard error of the means. Density of aquatic prey appeared to decrease in the smaller order streams, and increased in the larger order streams from spring to summer; Although, only significance occurred in Poca Run and Crooked Fork (t-test, $p=0.025, p=0.027$, respectively). After aquatic dry mass obtained from the kicknet samples had been log-transformed to confirm normality, a two-way ANOVA for season, stream, stream $X$ season interaction with nested time of day was performed in program $R$. Significant difference occurred between streams $(F(3,16)=4.651, p=0.016)$ and between seasons $(F(1,16)=4.720, p=0.045)$, but not with a stream by season interaction $\left(F_{(3,16)}=0.141, p=0.93\right)$ nor for sampling periods within the same day $(F(4,16)=1.182$, $\mathrm{p}=0.36$ ). Based on these results, aquatic dry mass $(\mathrm{mg})$ for time of day and samples within the same season were pooled. Across individual streams, dry mass appears to decrease from spring to summer, though individual t-tests did not demonstrate significance due to low sample sizes. 


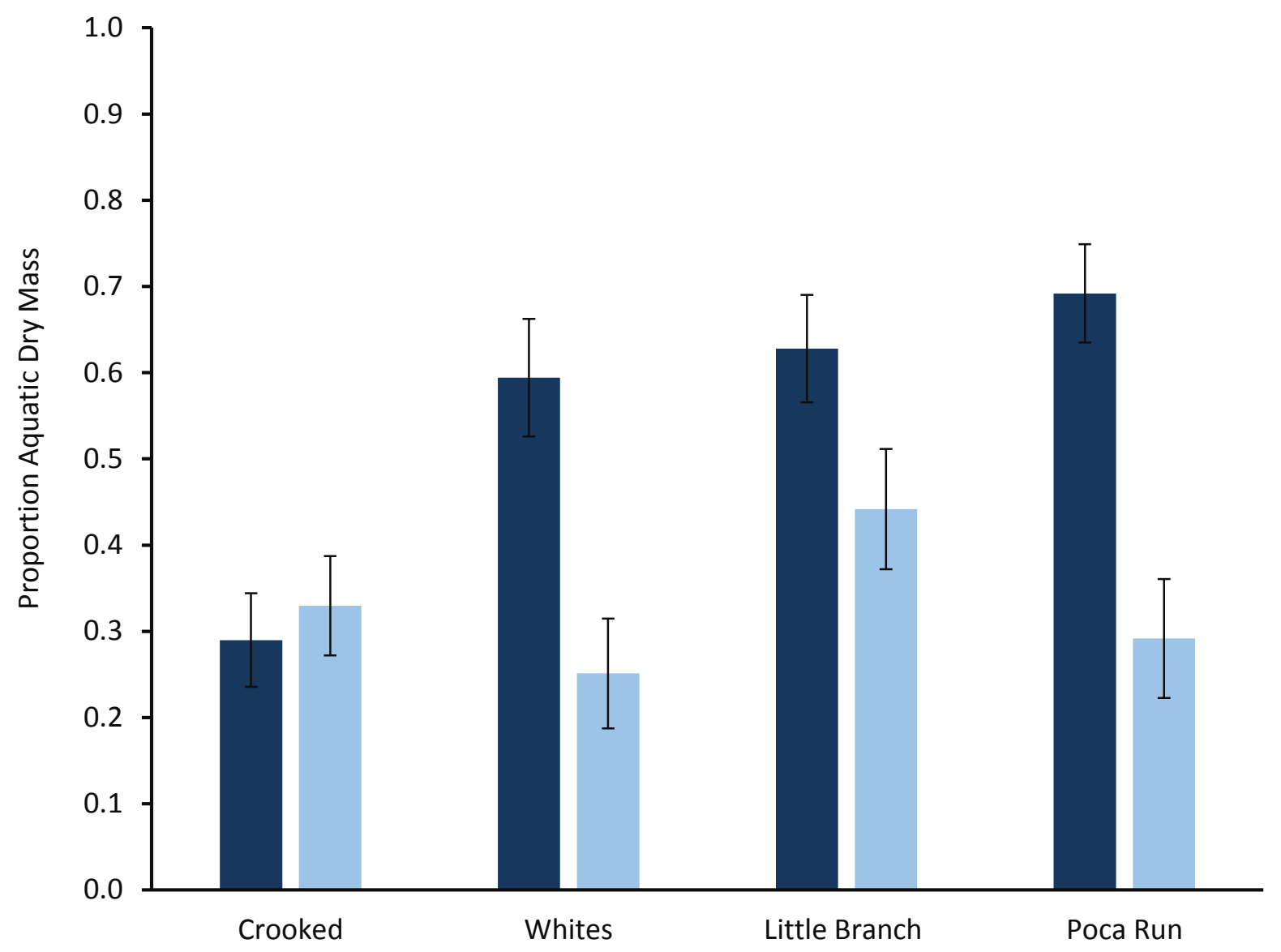

Figure 2.3. The proportion of aquatic macroinvertebrates present in each diet, averaged within streams for each season. Spring is depicted in dark blue and summer in light blue. Error bars represent standard error of the means. No differences in mean proportion of aquatic prey dry weight existed in diet samples between time of day (noon versus evening) in all streams and seasons except in the first summer samples in Poca Run (Mann Whitney U Test, $p=0.021$ ). No differences in mean proportion of aquatic prey dry weight existed between diet samples within the same season, pooled across time of day, in all streams and seasons except spring samples in Poca Run, and summer samples in Whites (Mann Whitney U Test, $p$-value $=0.033, p=0.012$, respectively). Therefore, all diets within the same season were pooled. Beta regression showed no significance was found in Little Branch or Crooked Fork ( $p=0.11, p=0.28$, respectively), However, both Poca and Whites Runs' aquatic prey proportions were significantly different from all other streams ( $p<0.001$ for each). As spring progressed into summer, Crooked Fork's aquatic proportions increased while Little Branch, Poca Run and Whites Run decreased as, but significance only occurred in Poca and Whites run (interaction with sampling date, $p=0.0039$, $p<0.001, p=0.22, p=0.44$, for Poca Run, Whites Run, Little Branch and Crooked Fork, respectively). 

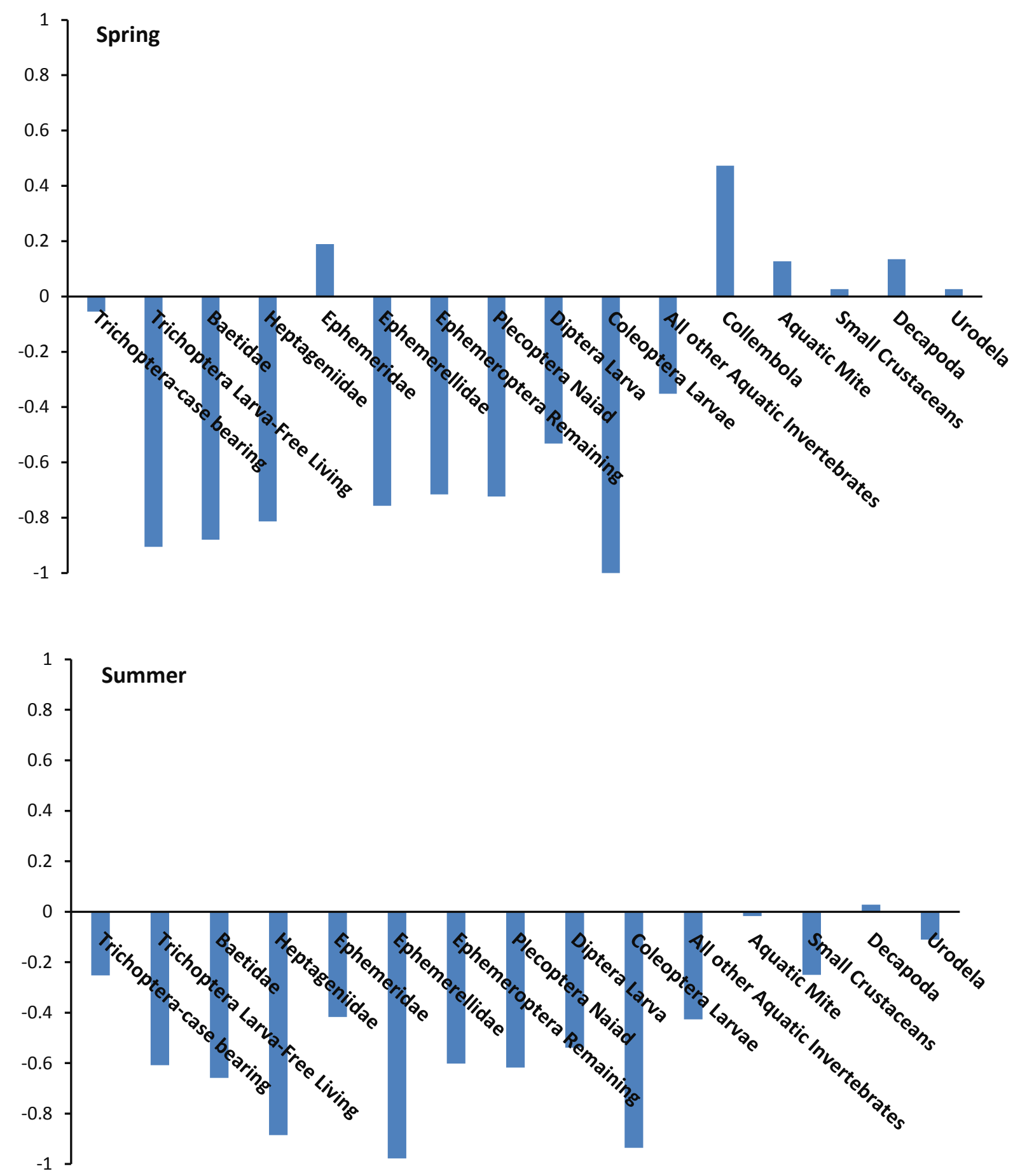

Figure 2.4. Results of Ivlev's Selectivity Index for Crooked Fork in spring and summer showing selection of a variety of aquatic prey categories based on abundance. Negative values indicate avoidance of prey item, positive values indicate selection and zero means neither avoidance nor selection. However, the more likely is the prey item is not found in the diets or kicknet samples. 

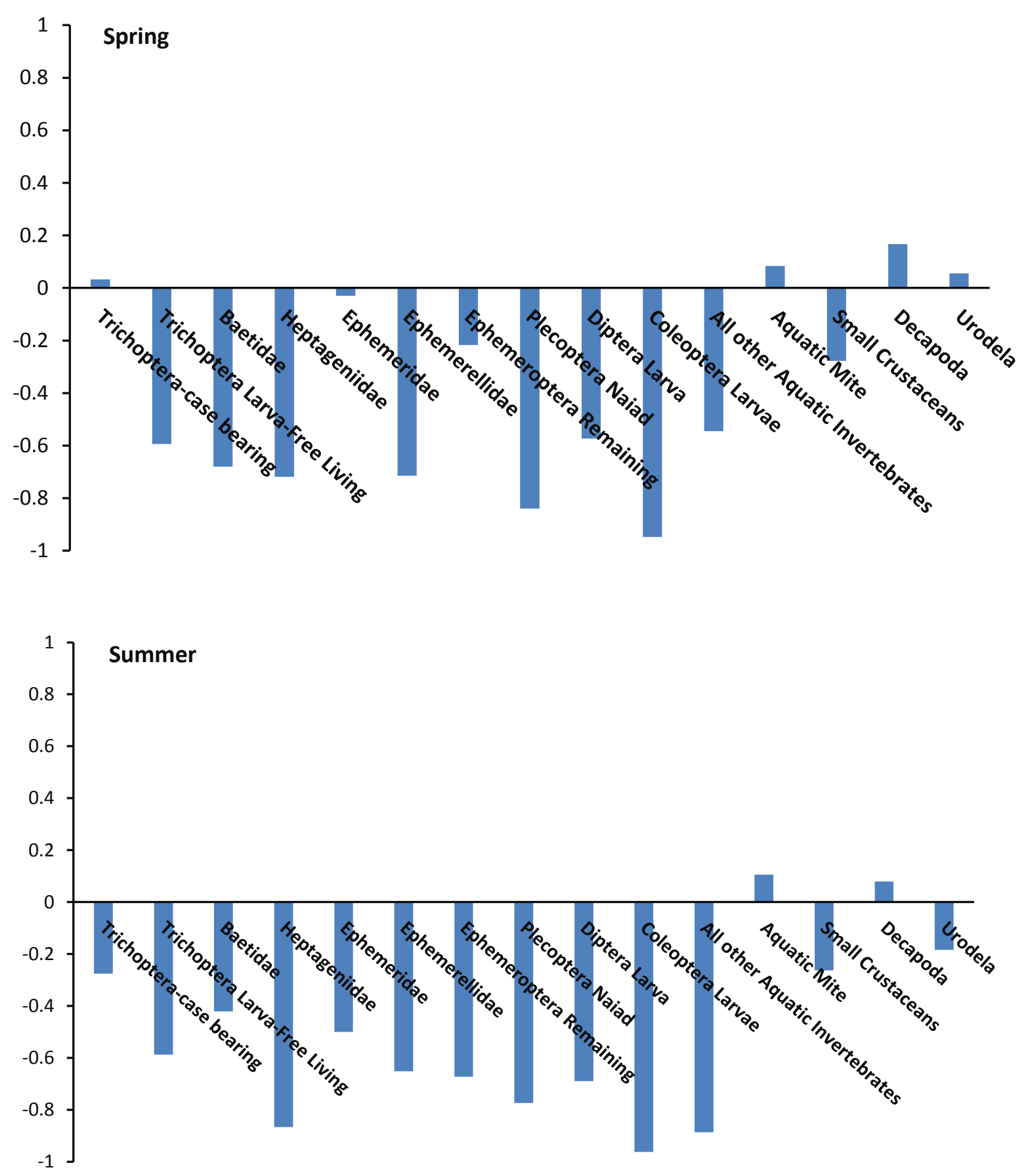

Figure 2.5. Results of Ivlev's Selectivity Index for Whites Run in spring and summer showing selection of aquatic prey categories based on abundance. Negative values indicate avoidance of prey item, positive values indicate selection and zero means neither avoidance nor selection. However, the more likely is the prey item is not found in the diets or kicknet samples. 

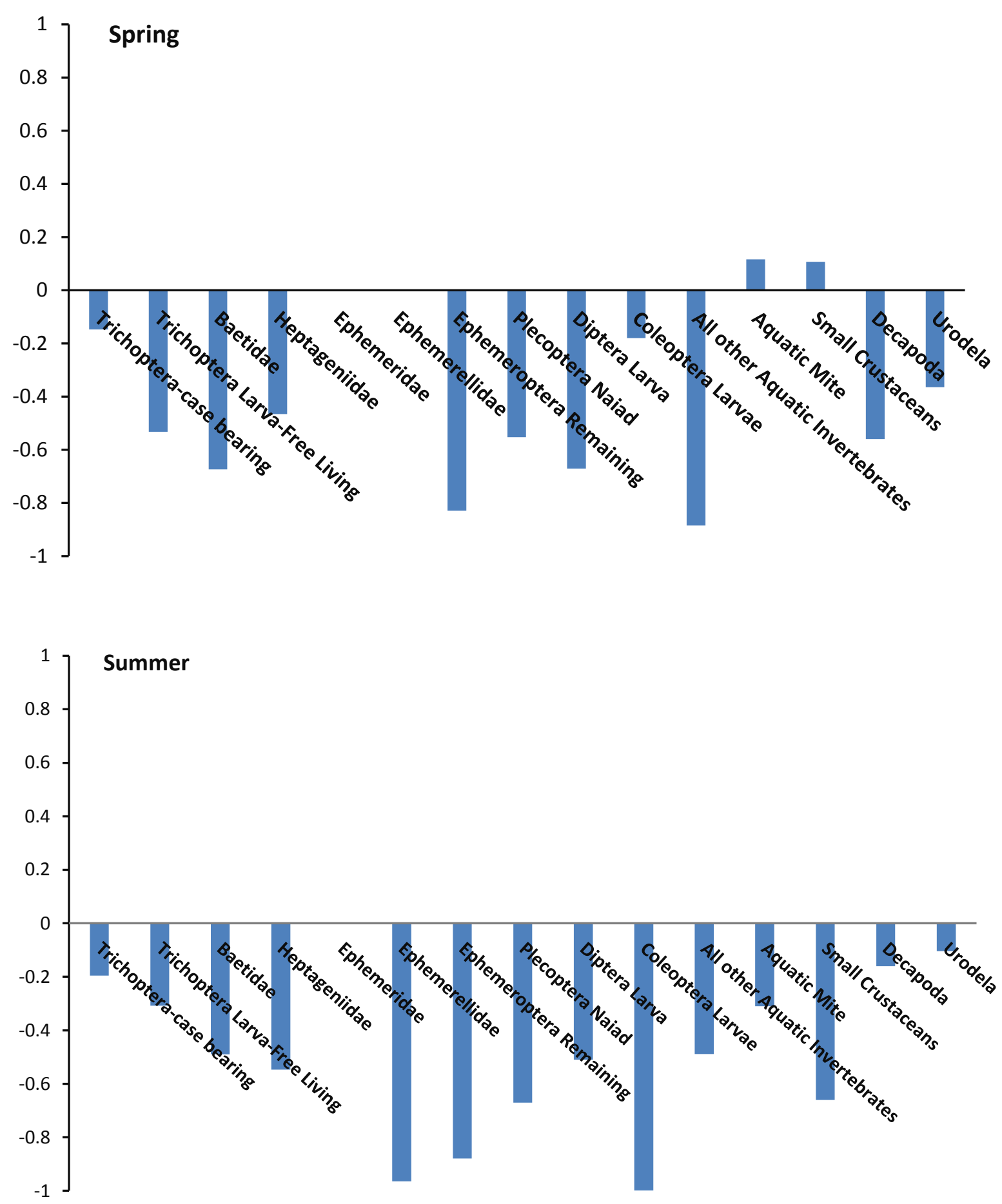

Figure 2.6. Results of Ivlev's Selectivity Index for Little Branch in spring and summer showing selection of aquatic prey categories based on abundance. Negative values indicate avoidance of prey item, positive values indicate selection and zero means neither avoidance nor selection. However, the more likely is the prey item is not found in the diets or kicknet samples. 

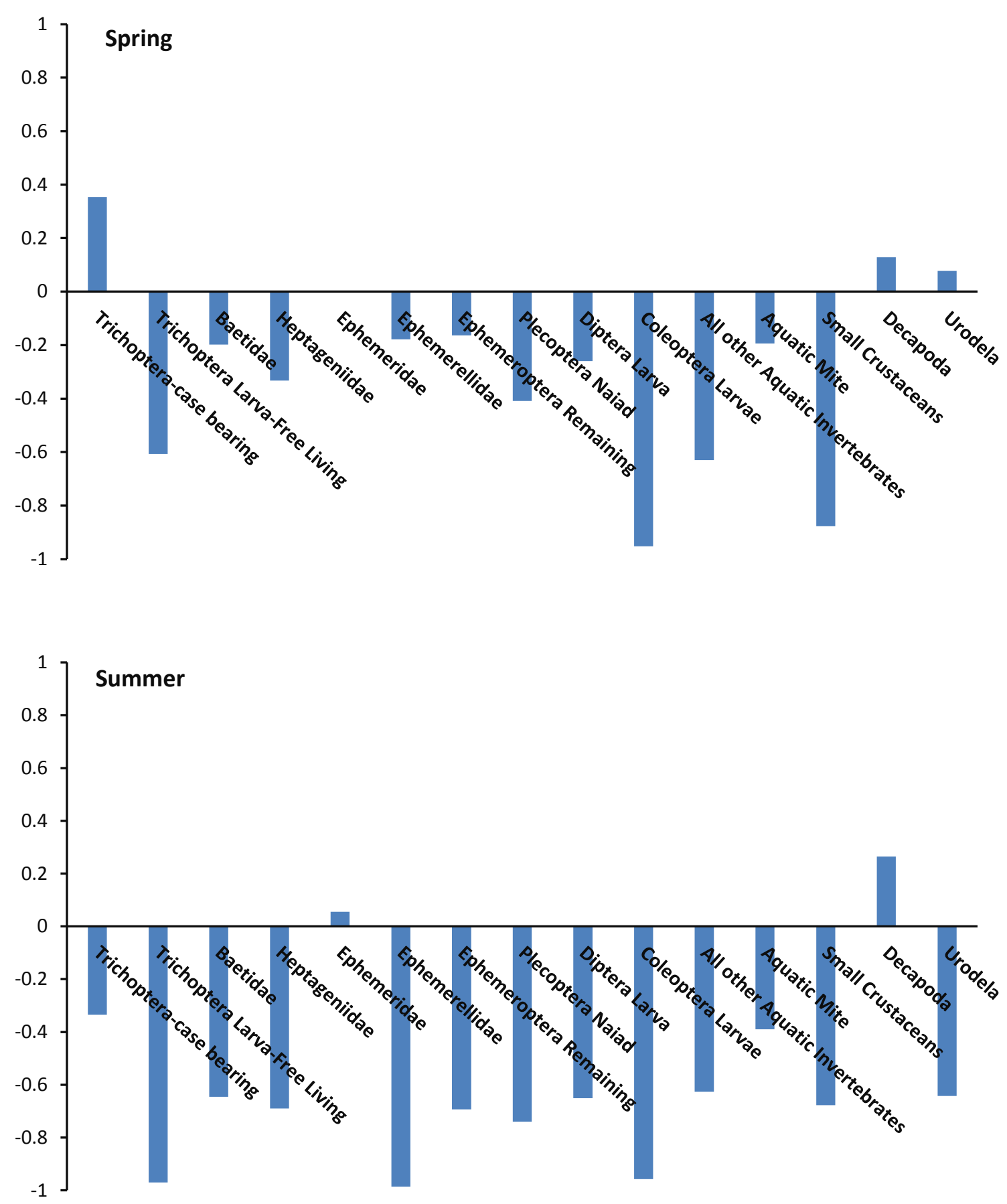

Figure 2.7. Results of Ivlev's Selectivity Index for Poca Run in spring and summer showing selection of aquatic prey categories based on abundance. Negative values indicate avoidance of prey item, positive values indicate selection and zero means neither avoidance nor selection. However, the more likely is the prey item is not found in the diets or kicknet samples. 


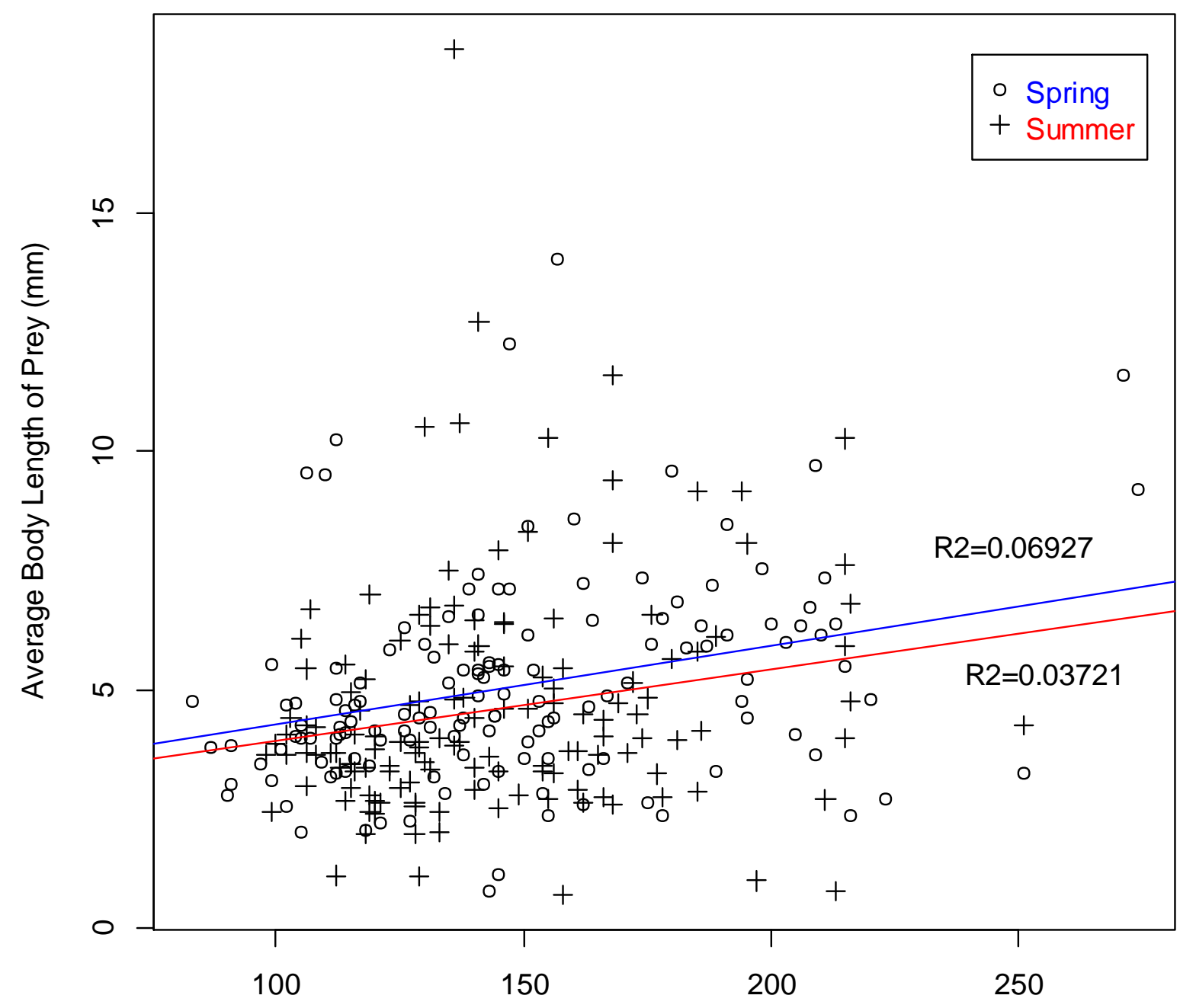

Fish Total Length $(\mathrm{mm})$

Figure 2.8. Individual fish length versus average body length of all prey items contained within each stomach content sample of all Brook Trout across all streams and both seasons. A general trend of larger fish selecting larger prey is evident (slope $=0.016, R^{2}=0.057, p<0.001$ ); trout may not be more size selective in spring versus summer (spring slope $=0.017, R^{2}=0.069, p<0.001$; summer slope $=0.015, R^{2}=0.037, p=0.013$ ), which was not statistically significant (ANCOVA $p$ value for interaction $=0.64$, in program JMP). 


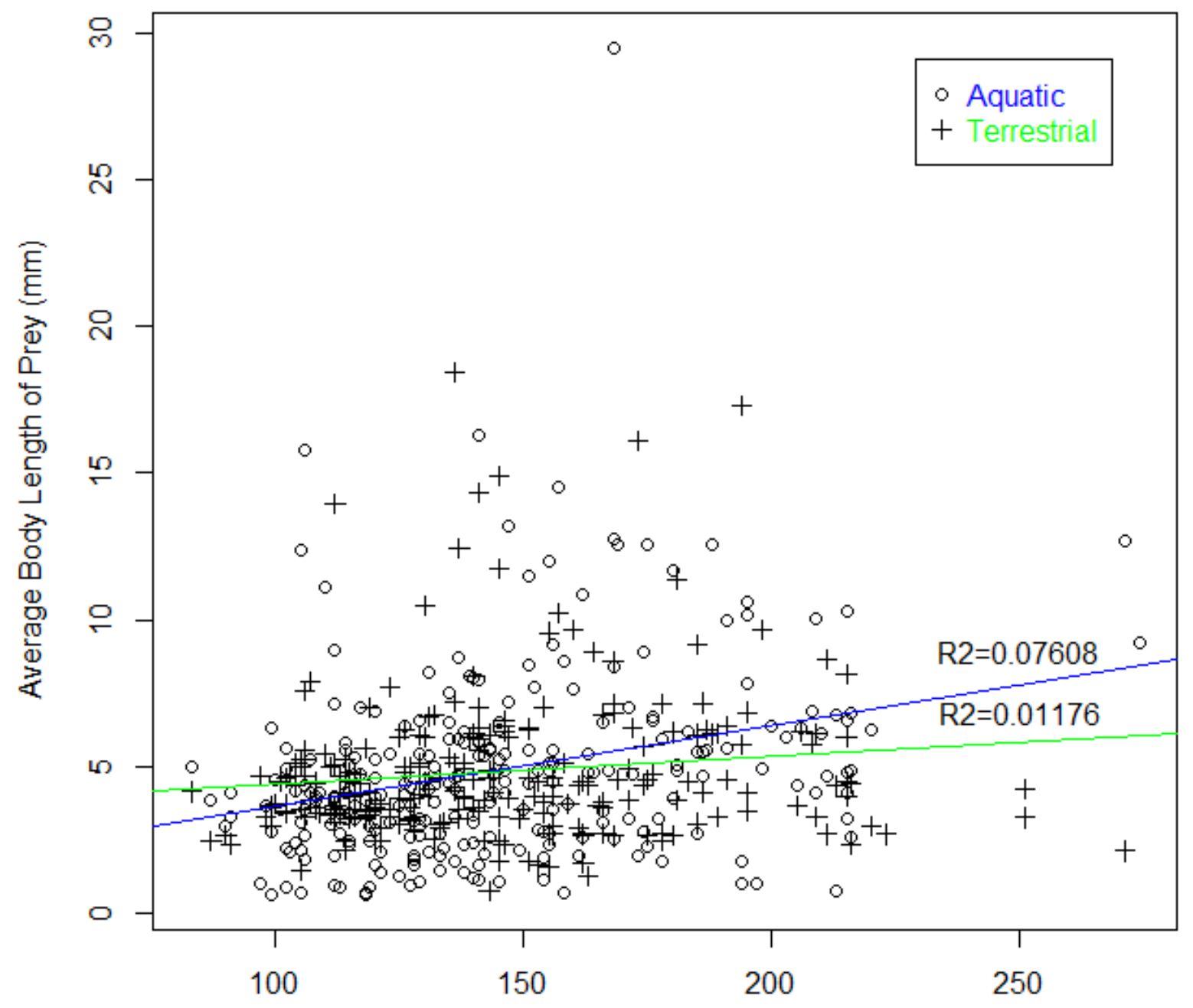

Fish Total Length ( $\mathrm{mm})$

Figure 2.9. Individual fish length compared against the average body length of all prey items contained within each stomach content sample of all Brook Trout across all streams and both seasons for aquatic and terrestrial prey. A general trend of larger fish selecting larger prey is evident (slope $=0.016, R^{2}=0.057, p=2.9$.e- 05 Trout are more selective of aquatic prey (slope= $0.028, R^{2}=0.076, p<0.001$ ) versus terrestrial prey (slope $\left.=0.0095, R^{2}=0.012, p=0.047\right)$, which was statistically significant (ANCOVA $p$-value for interaction $=0.017$, in program JMP). 


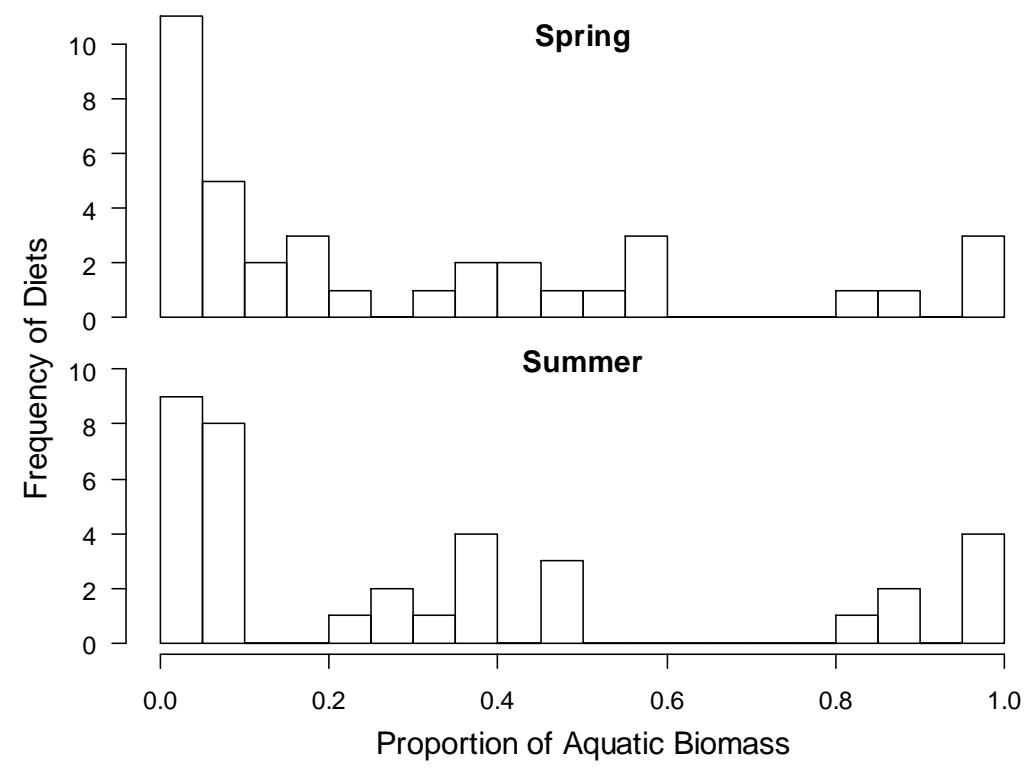

Figure 2.10. Histograms represented the frequency of diets (individual fish) with a certain proportion aquatic biomass for Crooked Fork across two seasons. Beta regression showed Crooked Fork did not significantly differ from all other streams nor with an interaction with season $(p=0.28$, interaction with season $\mathrm{p}=0.44)$.

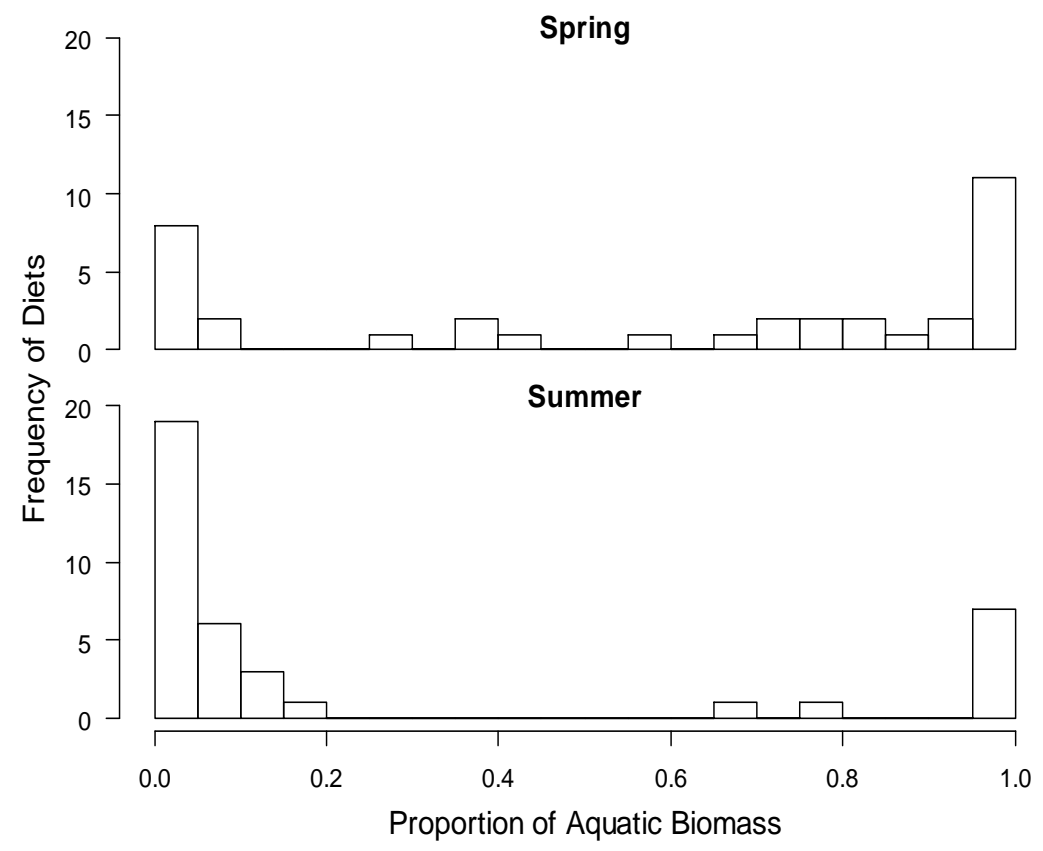

Figure 2.11. Histograms represented the frequency of diets (individual fish) with a certain proportion aquatic biomass for Whites Run across two seasons. Beta regression showed Whites Run was significantly different from all other streams as well as with an interaction with season $(p<0.001$, interaction with season $p<0.001$ ). 


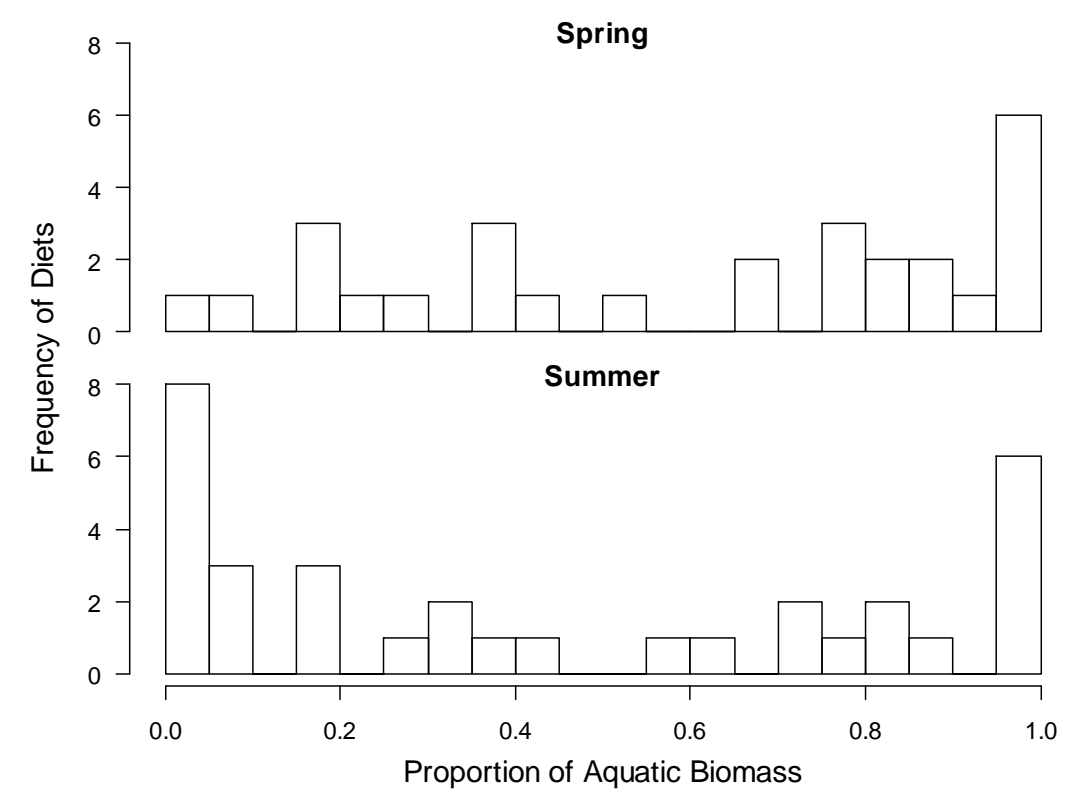

Figure 2.12. Histograms represented the frequency of diets (individual fish) with a certain proportion aquatic biomass for Little Branch across two seasons. Beta regression showed Little Branch did not significantly differ from all other streams nor with an interaction with season $(p=0.11$, interaction with season $p=0.22$ ).

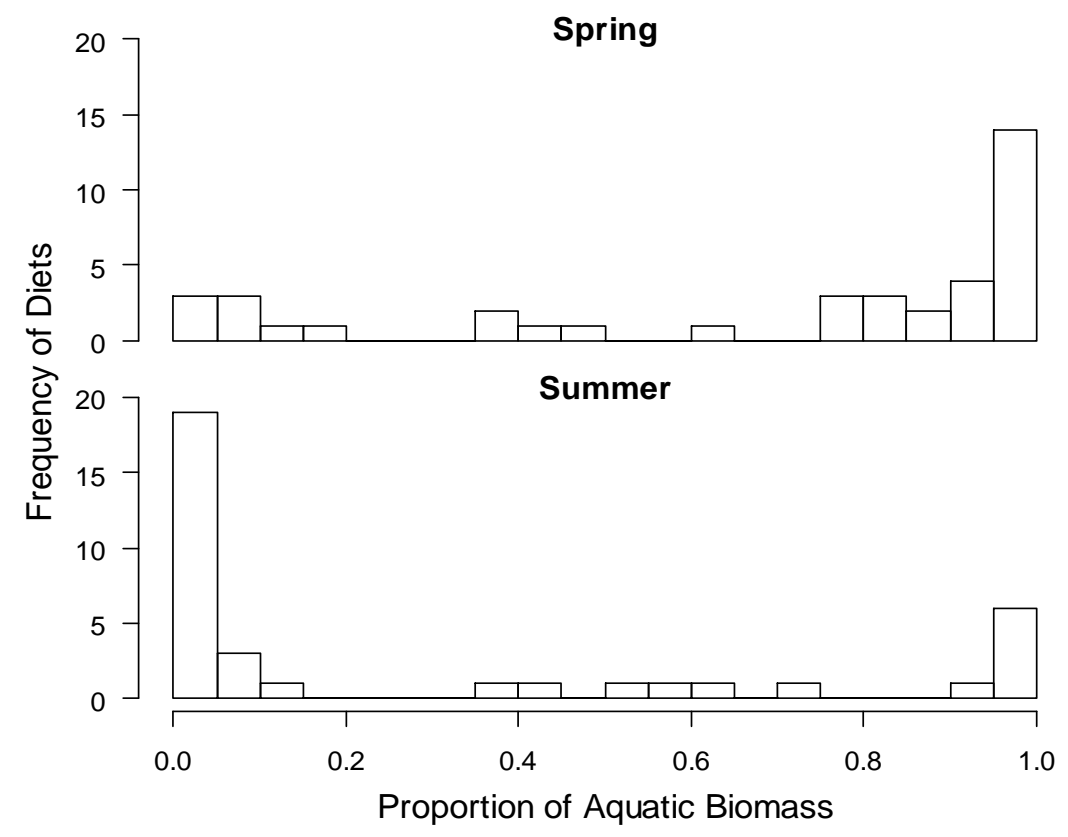

Figure 2.13. Histograms represented the frequency of diets (individual fish) with a certain proportion aquatic biomass for Poca Run across two seasons. Beta regression showed Poca Run was significantly different from all other streams as well as with an interaction with season $(p<0.001$, interaction with season $\mathrm{p}=0.0039$ ). 
Table 2.1. Watershed data for the streams selected and paired based on the drainage area and historical aquatic insect abundance category is presented below. Abundance of aquatic invertebrates a priori was derived from unpublished data (J. Stolarski) using a Surber sampler during spring 2006. Here, large-low refers to large drainage size and low abundance of aquatic invertebrates specifically insects. Large-high refers to large drainage area and high insect abundance, etc.

\begin{tabular}{|c|c|c|c|c|c|}
\hline Category & Stream & Watershed Description & Natershed Size $\left(\mathrm{km}^{2}\right)$ & Insect Density $\left(\# / \mathrm{m}^{2}\right)$ & Geology \\
\hline Large-Low & $\begin{array}{l}\text { Crooked } \\
\text { Fork }\end{array}$ & Tributary of the Old Field Fork of the Elk River & 13.6 & 311.3 & $\begin{array}{l}\text { Mauch } \\
\text { chunk }\end{array}$ \\
\hline $\begin{array}{l}\text { Large- } \\
\text { High }\end{array}$ & Whites Run & $\begin{array}{c}\text { Tributary of Scenea Creek of the North Fork of the } \\
\text { South Branch of Potomac }\end{array}$ & 12.7 & 1072 & Hampshire \\
\hline Small-Low & Little Branch & $\begin{array}{c}\text { Tributary of the Cranberry River of the Gauley } \\
\text { River }\end{array}$ & 2 & 499 & Pottsville \\
\hline $\begin{array}{l}\text { Small- } \\
\text { High }\end{array}$ & Poca Run & Tributary of East Fork of the Greenbrier River & 2.6 & 1154 & Chemung \\
\hline
\end{tabular}

Table 2.2. Metadata collected on study streams; Average \% canopy cover was acquired via densiometer; Average aquatic prey density, biomass, and individual mass was acquired via kicknet sampling. Large prey items such as Urodela and one large Decapoda was removed to prevent bias for average aquatic prey biomass, and average individual aquatic prey mass only.

\begin{tabular}{|c|c|c|c|c|c|c|}
\hline Category & Stream & $\begin{array}{c}\text { Water } \\
\text { Temp }\left({ }^{\circ} \mathrm{C}\right)\end{array}$ & $\begin{array}{c}\text { Average \% } \\
\text { Canopy Cover }\end{array}$ & $\begin{array}{c}\text { Average Aquatic Prey } \\
\text { Density }\left(\# / \mathrm{m}^{2}\right)\end{array}$ & $\begin{array}{c}\text { Average Aquatic } \\
\text { Prey Biomass (mg) }\end{array}$ & $\begin{array}{c}\text { Average Individual } \\
\text { Aquatic Prey Mass (mg) }\end{array}$ \\
\hline \multirow[t]{2}{*}{ Large-Low } & Crooked Spring & 13.6 & 81.51 & 782.1 & 86.6 & 0.46 \\
\hline & Crooked Summer & 14.3 & 85.55 & 1448.7 & 51.7 & 0.27 \\
\hline \multirow[t]{2}{*}{ Large-High } & Whites Spring & 15.5 & 84.64 & 1101.5 & 101.0 & 0.49 \\
\hline & Whites Summer & 16.0 & 81.25 & 1627.6 & 69.5 & 0.35 \\
\hline \multirow[t]{2}{*}{ Small-Low } & L. B. Spring & 12.8 & 86.98 & 1102.6 & 346.6 & 1.82 \\
\hline & L.B. Summer & 14.3 & 83.33 & 917.1 & 139.4 & 0.82 \\
\hline \multirow[t]{2}{*}{ Small-High } & Poca Spring & 11.9 & 79.69 & 2215.0 & 246.6 & 1.23 \\
\hline & Poca Summer & 13.4 & 86.98 & 818.7 & 151.1 & 0.45 \\
\hline
\end{tabular}


Table 2.3. Average total lengths including ranges of Brook Trout captured are presented below, along with density measurements from triple-pass electro-shocking sampling from fall 2013. No significant differences in average fish total lengths between seasons for each stream occurred. However, each stream-order pair had significant differences in fish total length averaged across seasons; Whites Run's average (167.2 mm) was significantly higher than Crooked Fork's average (129.5 mm, p<0.001), as well as Poca Run's average $(163.3 \mathrm{~mm})$ was significantly higher than Little Branch's average $(119.1 \mathrm{~mm}, \mathrm{p}<0.001)$.

\begin{tabular}{lccccccc}
\hline \multirow{2}{*}{ Stream } & \multicolumn{3}{c}{ Spring Fish Length $(\mathbf{m m})$} & \multicolumn{2}{c}{ Spring Fish Length (mm) } & \multicolumn{2}{c}{ Density from Longterm 2013 } \\
& $\mathbf{n}$ & Average & Range & n & Average & Range & data (fish length > 80 mm) \\
\hline Little Branch & 44 & 123.4 & $195-83$ & 52 & 115.6 & $176-89$ & 21.7 \\
Poca Run & 42 & 163.0 & $213-117$ & 44 & 163.6 & $216-119$ & 16.7 \\
Crooked Fork & 43 & 124.8 & $195-97$ & 41 & 134.4 & $202-98$ & 20.7 \\
Whites Run & 44 & 173.5 & $274-108$ & 53 & 161.9 & $264-112$ & 49.7 \\
\hline
\end{tabular}


Table 2.4. Results of Diet Indices in Crooked Fork- across spring and summer for the 13 most common prey groups. MNi and MWi refer to mean proportion by number and weight (displayed as percentage), respectively, for each prey. Oi and \%IRI refer to frequency of occurrence and percent index of relative importance for each prey type i.

\begin{tabular}{|c|c|c|c|c|c|c|c|c|c|}
\hline & \multirow[b]{2}{*}{ Prey Stage } & \multicolumn{4}{|c|}{ Crooked Spring $(\mathrm{N}=37)$} & \multicolumn{4}{|c|}{ Crooked Summer ( $\mathrm{N}=35)$} \\
\hline & & $\mathrm{MN}_{\mathrm{i}}$ & $\mathbf{M W}_{\mathbf{i}}$ & $\mathbf{O}_{\mathbf{i}}$ & \%IRI & $\mathrm{MN}_{\mathrm{i}}$ & $\mathbf{M W}_{\mathbf{i}}$ & $\mathbf{O}_{\mathrm{i}}$ & \%IRI \\
\hline EPT Naiad/Larvae & Aquatic & 12.3 & 12.6 & 75.7 & 14.1 & 15.1 & 10.9 & 68.6 & 15.5 \\
\hline Diptera & Aquatic & 3.6 & 2.4 & 35.1 & 1.6 & 9.1 & 3.4 & 54.3 & 5.9 \\
\hline Collembola & Aquatic & 10.9 & 3.9 & 59.5 & 6.6 & 26.6 & 8.7 & 80.0 & 24.6 \\
\hline Decapoda & Aquatic & 0.5 & 6.0 & 13.5 & 0.6 & 0.0 & 0.0 & 0.0 & 0.0 \\
\hline Trombidiformes & Aquatic & 2.0 & 0.6 & 27.0 & 0.5 & 2.5 & 0.4 & 17.1 & 0.6 \\
\hline Other Invertebrates ${ }^{1}$ & Aquatic & 0.7 & 0.0 & 10.8 & 0.1 & 2.0 & 6.0 & 22.9 & 0.2 \\
\hline Vertebrates & Aquatic & 0.2 & 2.6 & 2.7 & 0.1 & 0.2 & 2.8 & 2.9 & 1.9 \\
\hline Diptera & Terrestrial & 30.8 & 24.7 & 89.2 & 36.9 & 18.3 & 15.8 & 71.4 & 21.2 \\
\hline Coleoptera & Terrestrial & 15.2 & 17.7 & 75.7 & 18.6 & 7.1 & 11.9 & 51.4 & 8.5 \\
\hline EPT Adult & Terrestrial & 5.1 & 6.6 & 48.6 & 4.3 & 3.8 & 11.6 & 37.1 & 5.0 \\
\hline Hymenoptera & Terrestrial & 6.4 & 4.6 & 64.9 & 5.3 & 4.4 & 4.7 & 42.9 & 3.4 \\
\hline Hemiptera & Terrestrial & 3.3 & 1.2 & 43.2 & 1.5 & 2.4 & 4.8 & 34.3 & 2.1 \\
\hline Lepidoptera & Terrestrial & 0.9 & 2.7 & 18.9 & 0.5 & 1.0 & 5.2 & 22.9 & 1.2 \\
\hline Other Invertebrates ${ }^{2}$ & Terrestrial & 8.1 & 14.4 & 56.8 & 9.5 & 7.6 & 13.8 & 54.3 & 10.1 \\
\hline
\end{tabular}

Spring Includes: Hemiptera, Oribatida, Ostracoda; Summer Includes: Coleoptera larva \& adult, Hemiptera, Megaloptera, Odonata, Oribatida

${ }^{2}$ Spring Includes: Acari, Aranae, Diplopoda, Mecoptera, Neuroptera, Opiliones, Orthoptera, Psocoptera, Unknown Terrestrial Insecta; Summer Includes: Aranae, Chilopoda, Mecoptera, Opiliones, Orthoptera, Psocoptera, Unknown Terrestrial Insecta 
Table 2.5. Results of Diet Indices in Whites Run across spring and summer for the 13 most common prey groups. MNi and MWi refer to mean proportion by number and weight (displayed as percentage), respectively, for each prey. Oi and \%IRI refer to frequency of occurrence and percent index of relative importance for each prey type $i$.

\begin{tabular}{|c|c|c|c|c|c|c|c|c|c|}
\hline & \multirow[b]{2}{*}{ Prey Stage } & \multicolumn{4}{|c|}{ Whites Spring ( $\mathrm{N}=36)$} & \multicolumn{4}{|c|}{ Whites Summer ( $\mathrm{N}=39)$} \\
\hline & & $\mathrm{MN}_{\mathrm{i}}$ & $\mathbf{M W}_{\mathrm{i}}$ & $\mathbf{O}_{\mathbf{i}}$ & \%IRI & $\mathrm{MN}_{\mathrm{i}}$ & $\mathbf{M W}_{\mathbf{i}}$ & $\mathbf{O}_{i}$ & \%IRI \\
\hline EPT Naiad/Larvae & Aquatic & 46.5 & 47.1 & 83.3 & 64.1 & 16.1 & 10.1 & 56.4 & 13.2 \\
\hline Diptera & Aquatic & 3.0 & 0.5 & 36.1 & 1.0 & 2.8 & 0.3 & 33.3 & 0.9 \\
\hline Collembola & Aquatic & 6.1 & 0.5 & 50.0 & 2.7 & 2.5 & 0.7 & 15.4 & 0.4 \\
\hline Decapoda & Aquatic & 1.4 & 8.4 & 13.9 & 1.1 & 1.4 & 2.8 & 5.1 & 0.2 \\
\hline Trombidiformes & Aquatic & 0.2 & 0.0 & 2.8 & 0.0 & 0.5 & 0.1 & 7.7 & 0.0 \\
\hline Other Invertebrates ${ }^{1}$ & Aquatic & 0.1 & 0.2 & 5.6 & 0.0 & 0.7 & 1.2 & 5.1 & 0.1 \\
\hline Vertebrates & Aquatic & 0.1 & 2.7 & 2.8 & 0.1 & 1.1 & 7.3 & 7.7 & 0.6 \\
\hline Diptera & Terrestrial & 15.9 & 9.2 & 63.9 & 13.2 & 42.1 & 37.7 & 82.1 & 58.5 \\
\hline Coleoptera & Terrestrial & 6.8 & 10.7 & 38.9 & 5.6 & 5.1 & 7.9 & 46.2 & 5.4 \\
\hline EPT Adult & Terrestrial & 3.3 & 4.7 & 38.9 & 2.6 & 4.6 & 4.3 & 28.2 & 2.2 \\
\hline Hymenoptera & Terrestrial & 1.4 & 0.9 & 25.0 & 0.5 & 10.2 & 9.7 & 46.2 & 8.2 \\
\hline Hemiptera & Terrestrial & 5.0 & 2.1 & 8.3 & 0.5 & 2.7 & 1.2 & 28.2 & 1.0 \\
\hline Lepidoptera & Terrestrial & 0.6 & 1.9 & 36.1 & 0.7 & 3.2 & 6.6 & 33.3 & 2.9 \\
\hline Other Invertebrates ${ }^{2}$ & Terrestrial & 9.7 & 11.0 & 47.2 & 8.0 & 7.2 & 10.2 & 41.0 & 6.4 \\
\hline
\end{tabular}

Spring Includes: Coleoptera larvae \& adult, Oribatida; Summ

${ }^{2}$ Spring Includes: Acari, Aranae, Diplopoda, Neuroptera, Opiliones, Thysanoptera, Psocoptera, Unknown Terrestrial Insecta; Summer Includes: Aranae, Opiliones, Unknown Terrestrial Insecta 
Table 2.6. Results of Diet Indices in Little Branch across spring and summer for the 13 most common prey groups. MNi and MWi refer to mean proportion by number and weight (displayed as percentage), respectively, for each prey. Oi and \%IRI refer to frequency of occurrence and percent index of relative importance for each prey type i.

\begin{tabular}{|c|c|c|c|c|c|c|c|c|c|}
\hline & \multirow[b]{2}{*}{ Prey Stage } & \multicolumn{4}{|c|}{ Little Branch Spring (28) } & \multicolumn{4}{|c|}{ Little Branch Summer ( $\mathrm{N}=33$ ) } \\
\hline & & $\mathrm{MN}_{\mathrm{i}}$ & $\mathbf{N W}_{\mathbf{i}}$ & $\mathbf{O}_{\mathrm{i}}$ & \%IRI & $\mathrm{MN}_{\mathrm{i}}$ & $\mathbf{N W}_{\mathbf{i}}$ & $\mathbf{O}_{\mathrm{i}}$ & \%IRI \\
\hline EPT Naiad/Larvae & Aquatic & 39.1 & 38.9 & 82.1 & 53.8 & 18.9 & 12.5 & 78.8 & 22.1 \\
\hline Diptera & Aquatic & 10.8 & 2.7 & 60.7 & 6.9 & 5.2 & 0.7 & 51.5 & 2.7 \\
\hline Collembola & Aquatic & 4.5 & 1.0 & 42.9 & 2.0 & 8.1 & 0.6 & 45.5 & 3.5 \\
\hline Decapoda & Aquatic & 2.5 & 9.1 & 17.9 & 1.7 & 3.8 & 19.2 & 24.2 & 5.0 \\
\hline Trombidiformes & Aquatic & 0.3 & 0.0 & 7.1 & 0.0 & 0.1 & 0.0 & 3.0 & 0.0 \\
\hline Other Invertebrates ${ }^{1}$ & Aquatic & 4.2 & 1.9 & 25.0 & 1.3 & 1.9 & 1.7 & 18.2 & 0.6 \\
\hline Vertebrates & Aquatic & 0.6 & 5.8 & 7.1 & 0.4 & 1.5 & 8.3 & 9.1 & 0.8 \\
\hline Diptera & Terrestrial & 19.8 & 18.3 & 75.0 & 24.0 & 29.5 & 22.2 & 78.8 & 36.5 \\
\hline Coleoptera & Terrestrial & 4.9 & 3.9 & 46.4 & 3.4 & 2.6 & 3.1 & 36.4 & 1.9 \\
\hline EPT Adult & Terrestrial & 5.2 & 10.8 & 28.6 & 3.8 & 6.5 & 11.3 & 45.5 & 7.2 \\
\hline Hymenoptera & Terrestrial & 2.0 & 0.9 & 14.3 & 0.3 & 3.6 & 2.4 & 36.4 & 1.9 \\
\hline Hemiptera & Terrestrial & 1.1 & 0.7 & 7.1 & 0.1 & 5.1 & 2.4 & 51.5 & 3.5 \\
\hline Lepidoptera & Terrestrial & 1.1 & 2.8 & 10.7 & 0.3 & 4.1 & 9.0 & 48.5 & 5.7 \\
\hline Other Invertebrates ${ }^{2}$ & Terrestrial & 3.7 & 3.3 & 32.1 & 1.9 & 9.1 & 6.6 & 60.6 & 8.6 \\
\hline
\end{tabular}

${ }^{1}$ Spring Includes: Amphipoda, Coleoptera, Oribatida, Unknown Aquatic Insecta; Summer Includes: Amphipoda, Clodocera, Oribatida, Unknown Aquatic Insecta

${ }^{2}$ Spring Includes: Aranae, Diplopoda, Psocoptera, Unknown Terrestrial Insecta; Summer Includes: Aranae, Mecoptera, Opiliones, Psocoptera, Unknown Terrestrial Insecta 
Table 2.7. Results of Diet Indices in Poca Run across spring and summer for the 13 most common prey groups. MNi and MWi refer to mean proportion by number and weight (displayed as percentage), respectively, for each prey. Oi and \%IRI refer to frequency of occurrence and percent index of relative importance for each prey type i.

\begin{tabular}{|c|c|c|c|c|c|c|c|c|c|}
\hline & \multirow[b]{2}{*}{ Prey Stage } & \multicolumn{4}{|c|}{ Poca Run Spring ( $\mathrm{N}=39$ ) } & \multicolumn{4}{|c|}{ Poca Summer $(\mathrm{N}=36)$} \\
\hline & & $\mathbf{M N}_{\mathrm{i}}$ & $N_{\mathbf{i}}$ & $\mathbf{O}_{i}$ & \%IRI & $\mathrm{MN}_{\mathrm{i}}$ & $N_{\mathbf{i}}$ & $\mathbf{O}_{i}$ & \%IRI \\
\hline EPT Naiad/Larvae & Aquatic & 53.7 & 49.3 & 92.3 & 75.9 & 12.2 & 3.7 & 12.2 & 10.3 \\
\hline Diptera & Aquatic & 10.1 & 1.2 & 20.5 & 1.8 & 5.5 & 0.4 & 5.5 & 1.6 \\
\hline Collembola & Aquatic & 1.1 & 0.1 & 0.0 & 0.0 & 2.9 & 0.5 & 2.9 & 0.2 \\
\hline Decapoda & Aquatic & 1.2 & 11.2 & 28.2 & 2.8 & 5.9 & 18.1 & 5.9 & 4.2 \\
\hline Trombidiformes & Aquatic & 0.0 & 0.0 & 7.7 & 0.0 & 0.1 & 0.0 & 0.1 & 0.0 \\
\hline Other Invertebrates ${ }^{1}$ & Aquatic & 4.3 & 3.0 & 56.4 & 3.3 & 3.2 & 3.8 & 3.2 & 5.5 \\
\hline Vertebrates & Aquatic & 0.3 & 6.1 & 20.5 & 1.0 & 0.6 & 2.5 & 0.6 & 0.6 \\
\hline Diptera & Terrestrial & 13.1 & 9.9 & 51.3 & 9.4 & 31.1 & 19.1 & 31.1 & 19.1 \\
\hline Coleoptera & Terrestrial & 1.4 & 3.1 & 10.3 & 0.4 & 2.1 & 3.6 & 2.1 & 1.7 \\
\hline EPT Adult & Terrestrial & 9.2 & 5.8 & 12.8 & 1.5 & 4.9 & 3.3 & 4.9 & 3.1 \\
\hline Hymenoptera & Terrestrial & 0.4 & 0.2 & 20.5 & 0.1 & 2.9 & 2.1 & 2.9 & 1.6 \\
\hline Hemiptera & Terrestrial & 0.3 & 0.0 & 20.5 & 0.0 & 0.0 & 0.0 & 0.0 & 0.0 \\
\hline Lepidoptera & Terrestrial & 1.5 & 6.1 & 30.8 & 1.9 & 2.8 & 4.8 & 2.8 & 2.4 \\
\hline Other Invertebrates ${ }^{2}$ & Terrestrial & 3.4 & 3.9 & 30.8 & 1.8 & 21.9 & 36.7 & 21.9 & 49.6 \\
\hline
\end{tabular}

${ }^{1}$ Spring Includes: Amphipoda, Coleoptera larvae \& adult, Hemiptera, Odonata, Unknown Aquatic Insecta; Summer Includes: Amphipoda, Megaloptera, Ostracoda, Unknown Aquatic Insecta ${ }^{2}$ Spring Includes: Aranae, Opiliones, Unknown Terrestrial Insecta; Summer Includes: Aranae (1.55\%), Mecoptera (0.63\%), Neuroptera (0.014\%), Opiliones (0.11 \%), Orthoptera (47.29\%), Psocoptera (0.012\%), Unknown Terrestrial Insecta (0.046\%). 


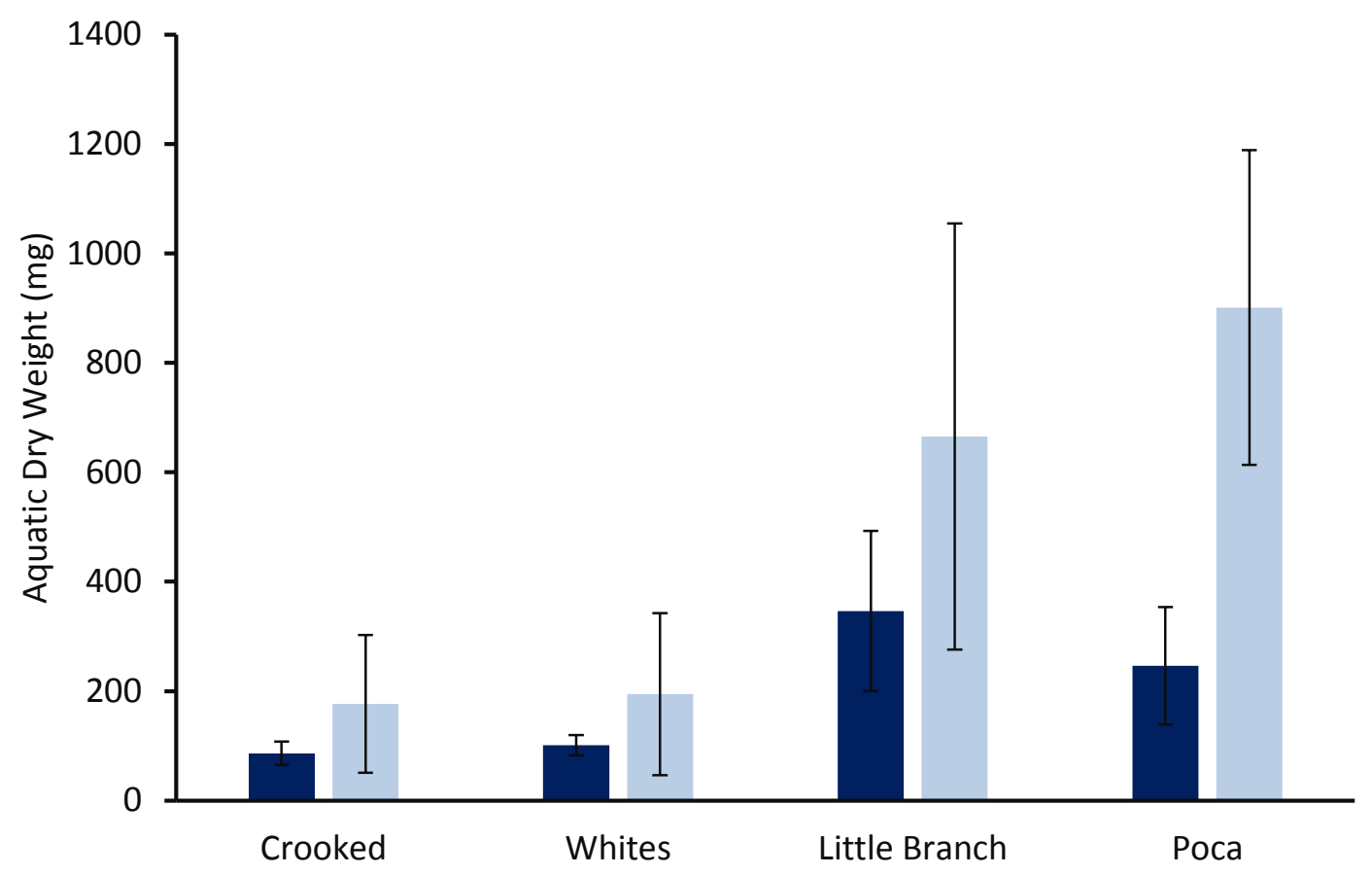

Appendix 2.1. Dry mass (mg) of aquatic prey collected via kicknet sampling for each stream. Error bars represent the standard error of the means. Large prey items, including Urodela and one large Decapoda, were included. Spring is depicted in dark blue and summer in light blue.

Appendix 2.2. Additional fish species found in each stream during Brook Trout collection via electroshocking and gastric lavage sample collection for diet study.

\begin{tabular}{lcccc}
\hline Species Common and Scientific Name & $\begin{array}{l}\text { Crooked } \\
\text { Fork }\end{array}$ & $\begin{array}{l}\text { Whites } \\
\text { Run }\end{array}$ & $\begin{array}{l}\text { Little } \\
\text { Branch }\end{array}$ & $\begin{array}{l}\text { Poca } \\
\text { Run }\end{array}$ \\
\hline Mottle Sculpin (Cottus bairdii) & $\mathrm{X}$ & $\mathrm{X}$ & $\mathrm{X}$ \\
Blue Ridge Sculpin (Cottus caeruleomentum) & & $\mathrm{X}$ & $\mathrm{X}$ \\
Fantail Darter (Etheostoma flabellare) & $\mathrm{X}$ & $\mathrm{X}$ & $\mathrm{X}$ \\
Creek Chub (Semotilus atromaculatus) & $\mathrm{X}$ & & $\mathrm{X}$ \\
Longnose Dace (Rhinichthys cataractae) & $\mathrm{X}$ & $\mathrm{X}$ & $\mathrm{X}$ \\
Western Blacknose Dace (Rhinichthys obtusus) & & $\mathrm{X}$ & $\mathrm{X}$ \\
Eastern Blacknose Dace (Rhinichthys atratulus) & $\mathrm{X}$ & & \\
Rosyside Dace (Clinostomus funduloides) & & $\mathrm{X}$ & \\
Northern Hogsucker (Hypentelium nigricans) & & $\mathrm{X}$ & \\
Rainbow Trout (Oncorhynchus mykiss) & & &
\end{tabular}

